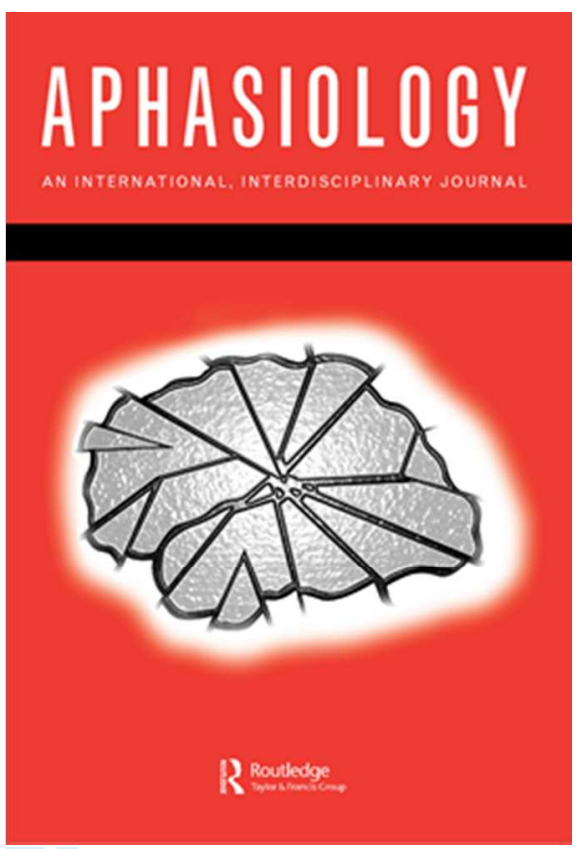

\title{
Morphosyntactic production in Greek- and Italian-speaking individuals with probable Alzheimer's disease: Evidence from subject-verb agreement, tense/time reference, and mood
}

\begin{tabular}{|r|l|}
\hline Journal: & Aphasiology \\
\hline Manuscript ID & APH-SI 16-104.R3 \\
\hline Manuscript Type: & Special Issue \\
\hline Date Submitted by the Author: & n/a \\
\hline Complete List of Authors: & $\begin{array}{l}\text { Fyndanis, Valantis; University of Oslo, MultiLing/Department of Linguistics } \\
\text { and Scandinavian Studies; University of Potsdam, Department of } \\
\text { Linguistics } \\
\text { Arfani, Dimitra; National and Kapodistrian University of Athens, School of } \\
\text { Philology/Department of Linguistics } \\
\text { Varlokosta, Spyridoula; National and Kapodistrian University of Athens, } \\
\text { School of Philology/Department of Linguistics } \\
\text { Burgio, Francesca; Fondazione Ospedale San Camillo; University of Padua, } \\
\text { Department of Neurosciences } \\
\text { Maculan, Anna; University of Padua, School of Medicine } \\
\text { Miceli, Gabriele; University of Trento, CIMEC/Department of Psychology } \\
\text { and Cognitive Science } \\
\text { Arcara, Giorgio; San Camillo Hospital IRCCS } \\
\text { Palla, Fabio; University of Padua, Department of Neurosciences } \\
\text { Cagnin, Annachiara; University of Padua, Department of Neurosciences } \\
\text { Papageorgiou, Sokratis G.; National and Kapodistrian University of Athens - }\end{array}$ \\
\hline
\end{tabular}


2

3

4

5

6

7

8

9

10

11

12

13

14

15

16

17

18

19

20

21

22

23

24

25

26

27

28

29

30

31

32

33

34

35

36

37

38

39

40

41

42

43

44

45

46

47

48

49

50

51

52

53

54

55

56

57

58

59

60

URL: http://mc.manuscriptcentral.com/paph Email: c.f.s.code@exeter.ac.uk

Medical School, Cognitive Disorders/Dementia Unit, 2nd University Department of Neurology

Semenza, Carlo; University of Padua, Department of Neurosciences; Fondazione Ospedale San Camillo

Keywords: morphosyntactic production, Alzheimer's disease, subject-verb agreement, tense/time reference, mood

SCHOLARONE ${ }^{m}$

Manuscripts 


\section{Morphosyntactic production in Greek- and Italian-speaking individuals with probable Alzheimer's disease: Evidence from subject-verb agreement, tense/time reference, and $\operatorname{mood}$}

Background: In probable Alzheimer's disease (AD) different memory systems, executive functioning, visuospatial recognition, and language are impaired. Regarding the latter, only a few studies have investigated morphosyntactic production thus far.

Aims: This study, which is a follow-up on Fyndanis, Manouilidou, Koufou, Karampekios, and Tsapakis (2013), investigates whether verb-related morphosyntactic production is (selectively) impaired in AD focusing on two highly inflected languages, Greek and Italian. The morphosyntactic phenomena explored are subject-verb Agreement, Tense/Time Reference, and Mood. Focusing on these phenomena allows us to investigate if recent hypotheses, originally developed in aphasia research, can also capture results related to AD. We tested the hypotheses discussed in Fyndanis et al. (2013), that is, the Interpretable Features' Impairment Hypothesis (e.g., Fyndanis, Varlokosta, \& Tsapkini, 2012) and the PAst DIscourse LInking Hypothesis (Bastiaanse, Bamyaci, Hsu, Lee, Yarbay Duman, \& Thompson, 2011). Methods \& Procedures: Two sentence completion tasks testing the production of subject-verb Agreement, Tense/Time Reference, and Mood were administered to 16 Greek-speaking and 10 Italian-speaking individuals with mild-to-moderate AD, as well as to 16 Greek-speaking and 11 Italian-speaking neurologically intact individuals who were matched with the participants with AD on age and education. Mixed-effects models were fitted to the data.

Outcomes \& Results: At the group level, both the Greek and Italian participants with AD performed worse than the controls. Both AD groups revealed selective patterns of morphosyntactic production (Greek: Agreement/Mood > Time Reference; Italian: Agreement > 
Time Reference $>$ Mood). Past Reference and Future Reference did not dissociate in any of the two AD groups. Nevertheless, in all four participants with AD who showed dissociations, Past Reference was more impaired than Future Reference.

Conclusions: The results indicate that the production of verb-related morphosyntactic categories can be impaired in mild-to-moderate AD. The different patterns observed in the two languages are partly attributable to the different way these languages encode Mood. The group results (of both the Greek- and Italian-speaking participants with AD) do not lend support to the PAst DIscourse LInking Hypothesis (Bastiaanse et al., 2011), whereas only the results of the Italian AD group are fully consistent with the Interpretable Features' Impairment Hypothesis (e.g., Fyndanis et al., 2012). However, the individual data are consistent with the PAst DIscourse LInking Hypothesis, and the Interpretable Features' Impairment Hypothesis is informed by the present data and modified accordingly, so that it can capture cross-linguistic patterns of morphosyntactic impairment. 


\section{INTRODUCTION}

In probable Alzheimer's disease (AD) several cognitive domains are impaired, which involve episodic memory, semantic memory, prospective memory, working memory (WM), executive functioning, visuospatial recognition, and language (e.g., Becker \& Overman, 2002; Hodges \& Patterson, 1995; Kempler, 2005). As far as language is concerned, it has been argued that predominantly naming abilities and sentence comprehension are impaired in mild-to-moderate AD (Kempler, 1995, pp. 184-185). Relatedly, the majority of linguistically-oriented studies on AD focus on the lexical-semantic domain (e.g., Almor et al., 2009; Aronoff et al., 2006; Bowles, Obler, \& Albert, 1987; Druks et al., 2006; Harciarek \& Kertesz, 2009; Kempler, Andersen, \& Henderson, 1995; Kim \& Thompson, 2004; Masterson et al., 2007; Robinson, Grossman, WhiteDevine, \& D'Esposito, 1996; Whatmough \& Chertkow, 2002) and on sentence comprehension (e.g., Kempler, Almor, MacDonald, \& Andersen, 1999; Kempler, Almor, Tyler, Andersen, \& MacDonald, 1998; Rochon, Waters, \& Caplan, 1994, 2000; Waters \& Caplan, 2002). To date, only a few studies have investigated sentence production abilities (see, for example, Altmann, 2004; Bencini et al., 2011; Kavé \& Levy, 2003; Kempler, Curtiss, \& Jackson, 1987; Kemper, LaBarge, Ferraro, Cheung, \& Storandt, 1993) and morphosyntactic production abilities of participants with $\mathrm{AD}$ (for a recent systematic review on inflectional morphology in $\mathrm{AD}$ and primary progressive aphasia, see Auclair-Ouellet, 2015).

To focus on morphosyntactic production in AD, some studies had a narrow scope, focusing on Tense, and in particular on the role of regularity in the production of past tenses. Ullman et al. (1997), for example, employed a sentence completion task to elicit the production of past test, and found that English-speaking anomic AD speakers were more impaired in producing the past tense of irregular than of regular verbs. Based on these results and on findings from other neurological populations (involving individuals with neurodegenerative diseases other 
than $\mathrm{AD}$ and speakers with aphasia with lesions in anterior and posterior portions of their left hemisphere), they accounted for the dissociation between regular and irregular verbs by claiming that two different systems are critically involved in the past tense formation of regular and irregular verbs, namely the "procedural" system and the declarative memory system, respectively, which are localized in anterior and posterior portions of the left hemisphere, respectively. Since individuals with mild-to-moderate AD predominantly have atrophy in the medial temporal lobe, their declarative memory is impaired, which leads to a selective morphosyntactic impairment that predominantly affects irregular verbs. Ullman et al.'s (1997) finding has been replicated in Italian mild-to-moderate AD by Walenski, Sosta, Cappa, and Ullman (2009) in production tasks and Colombo, Fonti, and Stracciari (2009) in synonymy judgment and generation tasks. In addition to regularity, Cortese, Balota, Sergent-Marshall, Buckner, and Gold (2006) also manipulated consistency, which refers to "the degree to which verbs of similar orthography and phonology in the present tense have similar past tenses to the target" (p. 856). They tested 70 English-speaking individuals with mild AD and found that they performed $95 \%$ and $81 \%$ correct on the production of the past tense of consistent regular and consistent irregular verbs, respectively, and $86 \%$ and $77 \%$ correct on the production of the past tense of inconsistent regular and inconsistent irregular verbs, respectively.

Some other studies on (morpho)syntactic production on AD have a broader scope. Such studies were conducted by Kempler et al. (1987), Blanken, Dittman, Haas, and Wallesch (1987), Kavé and Levy (2003), Altmann, Kempler, and Andersen (2001), Sajjadi, Patterson, Tomek, and Nestor (2012), and Fyndanis, Manouilidou, Koufou, Karampekios, and Tsapakis (2013), among others. The former five studies elicited (semi)spontaneous speech, with Kempler et al. (1987) and Altmann et al. (2001) also employing constrained tasks. These five studies checked for morphosyntactic errors, among other things, and produced contradictory results. While Kempler 
et al. (1987), Blanken et al. (1987), and Kavé and Levy (2003) reported preserved morphosyntactic production in AD, Altmann et al. (2001) found that three of their ten participants with $\mathrm{AD}$ presented with agrammatic features (e.g., omission of required auxiliary verbs, production of incorrect closed-class words and argument structure). Similarly, Sajjadi et al. (2012) reported that their participants with $\mathrm{AD}$ made more verb inflection errors in a picture description task than the control participants. It should be noted, however, that the methods used in the above studies - predominantly analysis of (semi)spontaneous speech-were not constrained enough to target specific morphosyntactic categories and investigate whether verb-related morphosyntactic categories such as subject-verb Agreement, Tense/Time Reference, Mood, Aspect, and sentential Negation dissociate.

Fyndanis et al. (2013) addressed this gap. They used constrained tasks to test the ability of 10 Greek-speaking individuals with mild AD to produce and comprehend subject-verb Agreement (henceforth, Agreement), Tense/Time Reference (henceforth, Time Reference), and Aspect. In Time Reference, Fyndanis et al. (2013) did not manipulate the regularity variable. They only used regular verbs and elicited verb forms referring to the past and to the future. In speech production, which is of interest here, Fyndanis et al. found that participants with AD performed better on Agreement than on Time Reference and Aspect, and better on Time Reference than on Aspect (Agreement: 90\% correct; Time Reference: 77.4\% correct; Aspect: $37 \%$ correct). These results, thus, point to selective verb-related morphosyntactic impairment in AD. (The scope of the adjective selective here and henceforth is restricted to morphosyntactic production and refers to dissociations between verb-related morphosyntactic phenomena.) The authors employed the Interpretable Features' Impairment Hypothesis (IFIH) (e.g., Fyndanis, Varlokosta, \& Tsapkini, 2012), originally formulated in aphasia research, to account for the pattern of performance exhibited by their participants with AD. The IFIH, which employs the 
distinction between Logical Form interpretable and Logical Form uninterpretable features (Chomsky, 1995, 2000, 2001), posits that categories with interpretable features, such as Time Reference, Aspect and Mood, are more demanding in terms of processing resources than categories with uninterpretable features, such as Agreement. This is so because, while the former require integration of information from two distinct levels of representation (grammatical and conceptual/extra-linguistic), the latter involve implementation of grammatical knowledge only. Fyndanis et al.'s (2013) rationale for discussing a "processing hypothesis" originally developed in aphasia research in an AD study was the following: since morphosyntactic impairments in agrammatic aphasia have been partly attributed to processing or WM limitations (see, for example, Fyndanis et al., 2012; 2013; Kok, van Doorn, \& Kolk, 2006), and given individuals with AD have WM limitations (Baddeley, 1992, 1996; Baddeley, Bressi, Della Sala, Logie, \& Spinnler, 1991; Collette, Van der Linden, Bechet, \& Salmon, 1999; Kensinger, Shearer, Locascio, Growdon, \& Corkin, 2003; Morris \& Baddeley, 1988) -among other cognitive deficits-, similar patterns of morphosyntactic impairment are expected in both neurological conditions, which would be legitimately accounted for by the same hypothesis. Fyndanis et al.'s (2013) results were at odds with Kempler et al.'s (1987), Blanken et al.’s (1987), and Kavé and Levy's (2003), but consistent with Altmann et al.’s (2001) and Sajjadi et al.’s (2012), who reported morphosyntactic impairments in speech production in English AD. The performance of Fyndanis et al.'s (2013) participants with AD on Time Reference production cannot be directly compared to the AD results on regular Tense reported by Ullman et al. (1997), Walensky et al. (2009), Colombo et al. (2009), and Cortese et al. (1996), as none of the latter four studies tested future tense production. However, Fyndanis et al.'s results on Time Reference seem to be consistent at least with those of Ullman et al. (1997), since their participants with AD were mildly impaired in regular verbs $(89 \%$ correct compared to $98 \%$ correct by the control 
participants). Fyndanis et al. (2013) also discussed their Time Reference results in light of the PAst DIscourse LInking Hypothesis (PADILIH) (Bastiaanse et al., 2011), which was also originally formulated in aphasia research. ${ }^{1}$ The PADILIH posits that Past Reference is more demanding in terms of processing resources than Present/Future Reference, because, unlike the latter, it involves discourse linking (Zagona, 2003, 2013). Since individuals with AD are known to present processing limitations due to reduced verbal WM capacity (e.g., Baddeley, 1992, 1996; Baddeley et al., 1991; Collette et al., 1999; Kensinger et al., 2003; Morris \& Baddeley, 1988), the PADILIH should predict the same results for both aphasia and AD. The performance of the participants with AD in Fyndanis et al. (2013) on Time Reference were not consistent with the PADILIH. However, just like the IFIH (Fyndanis et al., 2012), the PADILIH (Bastiaanse et al., 2011) has to be tested with more participants with AD and in more than one language.

This study aims to further explore Fyndanis et al.'s (2013) main finding that verb-related morphosyntactic production is (selectively) impaired in AD focusing on two highly inflected languages, Greek and Italian. In both languages, we tested Agreement, Time Reference, and Mood. To our knowledge, Mood has never been investigated in AD. As will be shown in the next section, Mood is encoded differently in Greek and Italian, which enables us to investigate whether this difference gives rise to different patterns of performance in Greek and Italian AD. Focusing on these three verb-related categories allows us to investigate if indeed the IFIH (Fyndanis et al., 2012; Nanousi, Masterson, Druks, \& Atkinson, 2006; Varlokosta et al., 2006) can accommodate results related to AD, as suggested by Fyndanis et al. (2013). According to the IFIH, Time Reference and Mood (both of which carry interpretable features and involve integration processes) are expected to be more impaired than Agreement (which carries an uninterpretable feature and does not involve integration processes) in both Greek and Italian AD. Focusing on Greek and Italian, two languages that differ in the way relevant morphosyntactic 
categories are encoded, allows us to test the cross-linguistic validity of the IFIH. The Time Reference results will also be discussed in light of the PADILIH (Bastiaanse et al., 2011), which predicts worse performance on Past Reference than on Future Reference in both Greek- and Italian-speaking participants with AD. We will also explore the relationship between severity of dementia and verbal WM, on the one hand, and morphosyntactic production, on the other hand. Verbal WM capacity is potentially relevant for both hypotheses, as the processing resources required for the production of Agreement, Time Reference, and Mood may be related to this memory system. Fyndanis et al. (2013) implied that this is the case. If this assumption is correct, and given that Time Reference and Mood are more demanding than Agreement, and individuals with AD have a limited verbal WM capacity, the IFIH (Fyndanis et al., 2012) would expect WM scores to positively correlate with performance on Time Reference and Mood, but not with performance on Agreement. In the same vein, given that Past Reference is more demanding than Future Reference (Bastiaanse et al., 2001; Zagona, 2003, 2013), the PADILIH would expect WM scores to positively correlate with performance on Past Reference but not with performance on Future Reference. Finally, the Mood results will be discussed in light of Lapointe's (1985) hypothesis, according to which we would expect Indicative Mood, which is the unmarked Mood value (e.g., Warburton, 1973), to elicit higher performance than Subjunctive Mood.

\section{Background on Agreement, Tense/Time Reference, and Mood in Greek and Italian}

In both Greek and Italian, all finite verbs consist of a stem and one or more inflectional suffixes that express morphosyntactic phenomena such as Agreement (six values in each tense), Tense (past, present, future, among others), and Mood (indicative, subjunctive, among others). In Greek, while the past tense is monolectic (e.g., èpeksa ( $\grave{e}_{\text {past }}-$ peks $s_{\text {stem.perf.asp }}-a_{\text {past.1st.sg }}$ ) '(I) played'), the future tense is formed by the combination of the particle $\theta a$ with a finite non-past verb form 
(e.g., $\theta a$ pèks-o $\left(\theta a_{f u t}\right.$ pèks $s_{\text {stem.perf.asp }}$ - $\left._{\text {nonpast.1st.sg }}\right)$ '(I) will play'). The Italian Tense system features the reverse pattern because, at least in spoken Italian in Northern Italy (which is relevant for the present study), speakers usually refer to the past using periphrastic forms and to the future using

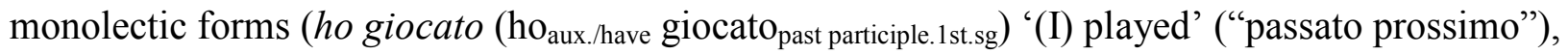
giocherò $\left(\right.$ gioch $\left._{\text {stem- }}-\mathrm{er}_{\text {fut }}-\mathrm{ò}_{1 \text { st.sg }}\right)$ '(I) will play').

As far as the term Mood is concerned, it "is used to refer to a formally differentiated verbal construction associated with a distinct characteristic function. In order to recognize a mood difference between verb forms, they have to be distinct either in their morphology (their inflectional endings) or in the choice of particles which precede and modify the verb forms. Mood, therefore, is viewed as a grammatically marked verbal category" (Holton, Mackridge, \& Philippaki-Warburton, 1997, p. 203). The three most common Mood values are Indicative, Subjunctive, and Imperative. The basic/characteristic function of the Indicative Mood is "to describe objectively an event or a state of affairs" (Holton et al., 1997, p. 204). On the other hand, the prototypical function of the Subjunctive Mood is "not to describe situations but to present them as wished for, desired, requested, ordered, conceded, allowed etc., on the part of the speaker in direct speech, or on the part of the main clause subject if the subjunctive occurs in a subordinate clause" (Holton et al., 1997, p. 205).

Greek and Italian present striking structural differences in the way they encode Mood. In Greek, the Subjunctive Mood is expressed formally by the use of the particles na and as, whereas in Italian the Subjunctive Mood is not realized by means of a particle, but by means of a distinct verb form (e.g., voglia/volessi). 


\section{METHODS}

\section{Participants}

We tested 16 Greek-speaking and 10 Italian-speaking individuals with mild-to-moderate AD as well as two age-and education-matched control groups. The Greek-speaking participants with AD were recruited from the Cognitive Disorders/Dementia Unit of the $2^{\text {nd }}$ Department of Neurology, “Attikon" University General Hospital, National and Kapodistrian University of Athens. The Italian-speaking participants with AD were recruited from the Neurology Clinic, Department of Neurosciences, of the University of Padua. All participants with AD met the NINCDS-ADRDA inclusion and exclusion criteria for a primary diagnosis of probable Alzheimer's disease (McKhann et al., 1984; McKhann et al., 2011). The severity of their condition (mild-to-moderate) was assessed on the basis of the Mini-Mental State Examination (MMSE) (Folstein, Folstein, \& McHugh, 1975), which is a measure of general cognitive functioning. The diagnosis for the Greek- and Italian-speaking participants with AD was made by cognitive neurologists SGP $\left(10^{\text {th }}\right.$ co-author) and AC ( $9^{\text {th }}$ author), respectively. Both Greek and Italian participants were administered a comprehensive neuropsychological battery, including two verbal WM tasks - the digit ordering span task (Fyndanis et al., 2013; MacDonald, Almor, Henderson, Kempler, \& Andersen, 2001) and the backward digit span task. In the digit ordering span task, participants hear a series of digits (e.g., 2, 8, 5, 4), which ranges from $2-6$ digits, and immediately report them back in ascending numerical order $(2,4,5,8)$. In the backward digit span task, the participant hears a series of digits (e.g., 2, 8, 5, 4), which ranges from $2-8$ digits, and immediately reports them back in reverse order of presentation $(4,5,8,2)$. In both WM tasks, the digits 1-9 were used to develop the experimental digit series. For both tasks, we used the scoring criteria employed by MacDonald et al. (2001), and following Waters and Caplan (2003), we calculated composite WM scores. The demographic and cognitive profile of the Greek and Italian 
participants is presented in Table 1. The two groups of individuals with AD differed significantly on MMSE scores $(\mathrm{t}(21)=-3.30, p=0.003)$, with the Greek group performing worse than the Italian group, but not on WM, age, and number of years of formal education.

//Insert Table 1 about here//

\section{Materials and procedures}

In both languages, we used two different sentence completion tasks to test Agreement and Time Reference (Task 1), and Mood (Task 2).

\section{Task 1}

Task 1 consisted of 80 items, half of which tested Agreement and half Time Reference. Each condition consisted of two subconditions. The Agreement condition consisted of person Agreement $(\mathrm{N}=20)$ and number Agreement $(\mathrm{N}=20)$, and the Time Reference condition consisted of Past Reference $(\mathrm{N}=20)$ and Future Reference $(\mathrm{N}=20)$. Twenty regular verbs were used in each language. ${ }^{2}$ Each verb appeared four times, once in each subcondition. Of the 40 target verb forms included in the Agreement condition, 20 were in $3^{\text {rd }}$ person and singular number (of which half were in past tense and half in future tense), and 20 in $3^{\text {rd }}$ person and plural number (of which half were in past tense and half in future tense). Likewise, in the Time Reference condition, 10 past reference items encoded $3^{\text {rd }}$ person and singular number, 10 past reference items encoded $3^{\text {rd }}$ person and plural number, 10 future reference items encoded $3^{\text {rd }}$ person and singular number, and 10 future reference items encoded $3^{\text {rd }}$ person and plural number. Items were pseudorandomised so that there were never more than three consecutive occurrences of the same condition; and 
sentences containing the same verb were always separated by at least three sentences that included different verbs.

Participants were auditorily presented with a source sentence (SS) and the beginning of a target sentence (TS). They were instructed to orally complete the TS producing the missing verb phrase. Only the verb forms provided by the participants were scored for correctness. In the Agreement condition Time Reference errors were ignored, and so were Agreement errors in the Time Reference condition. The items were presented in the same order to all participants. Examples of the Agreement and Time Reference conditions are given in (1a) and (1b), respectively. (Italian-speaking participants P2 and P8 did not complete this task because they were not available for an additional session.)

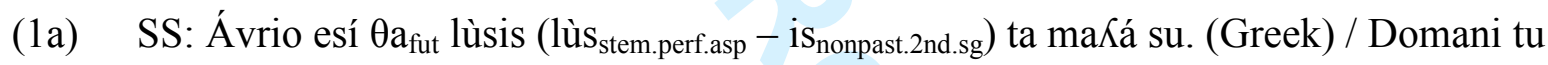
laverai $\left(\operatorname{lav}_{\text {stem }}-\mathrm{er}_{\text {fut }}-\mathrm{ai}_{\text {fut.2nd.sg }}\right)$ i capelli. (Italian)

'Tomorrow you will wash-sg your hair.'

TS: Ávrio aftós . (Greek) / Domani lui . (Italian) (target: $\theta \mathrm{a}$ lùsi $\left(\theta \mathrm{a}_{\text {fut }}\right.$ lùs $\left.\mathrm{stem.perfective} \mathrm{asp}-\mathrm{i}_{3 \text { rd.sg }}\right)$ ta maKá tu $($ Greek $) /$ laverà $\left(\operatorname{lav}_{\text {stem }}-\mathrm{er}_{\text {fut }}-\right.$

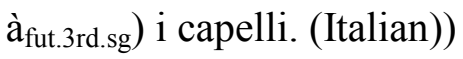

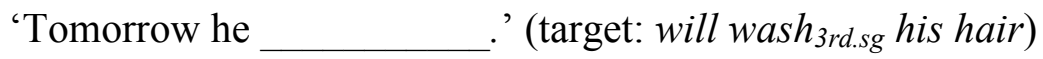

(1b) SS: Esí ávrio $\theta$ a lùsis $\left(\theta \mathrm{a}_{\text {fut }}\right.$ lùs $\left.\mathrm{s}_{\text {stem.perfective asp }}-\mathrm{is}_{2 \mathrm{nd.sg}}\right)$ ta maKá su. (Greek) / Tu domani laverai $\left(\operatorname{lav}_{\text {stem }}-\mathrm{er}_{\text {fut }}-\mathrm{ài}_{\text {fut.2ndg.sg }}\right)$ i capelli. (Italian)

'You tomorrow will wash-sg your hair.'

TS: Esí x $\theta$ és . (Greek) / Tu ieri . (Italian) 


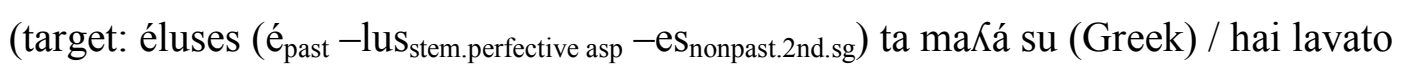

(hai aux.2nd.sg $_{\text {lavato }}$ past participle) i capelli. (Italian))

'You yesterday ' (lit.) (target: washed your hair)

\section{Task 2}

In both languages, Task 2 included 60 experimental items, half of which tested Indicative Mood and half Subjunctive Mood. Thirty verbs were used overall. Each verb appeared twice; once to elicit Indicative Mood and once to elicit Subjunctive Mood. However, the design of Task 2 in the two languages was not identical, since Greek and Italian encode Mood in different ways.

In Greek, participants were presented with a picture depicting an action and two persons, and one two-clause coordinate sentence (in the Indicative Mood condition; Figure 1a) or two oneclause sentences (in the Subjunctive Mood condition; Figure 1b). The experimenter started describing what was happening in the accompanying picture, initially focusing on one of the two persons and then directing the participant's attention to the second person. When the experimenter stopped speaking, the participant had to complete the utterance providing the missing verb phrase. All 60 target verb forms encoded $3^{\text {rd }}$ person and singular number. Agreement and Aspect errors were ignored. The items were presented in the same order to all participants.

//Insert Figure 1a about here//

//Insert Figure 1b about here// 
In the Italian version of Task 2, which did not involve pictures, all experimental items were conditional sentences. Only Indicative Mood in present tense (“indicativo presente”) and Subjunctive Imperfect ("congiuntivo imperfetto") were targeted in order to avoid eliciting structurally and computationally more demanding, periphrastic mood values (like (Se) avessi $\underline{\text { saputo }}$ '(If) I had known'). There was an even distribution of the singular and plural number values and of the three person values in the Indicative and in the Subjunctive Mood conditions, as well as in the task as a whole. The sentences of the two conditions were pseudorandomized, such that there were never more than three consecutive items of the same condition. A PowerPoint presentation was used. Participants were cross-modally presented with a sentence, in which the target verb form was missing from the subordinate clause. In the written sentence, the missing verb was substituted by an underscore symbol, and the infinitival form of the missing verb appeared within parentheses below the sentence. Participants were asked to orally provide the correct (inflected) verb form. Subordinate clauses always followed matrix clauses, because we wanted to ensure that, before providing the missing verb form, participants would first process the matrix clause, which determines the mood value of the subordinate clause's verb. Examples of Indicative and Subjunctive Mood items are given in (2a) and (2b), respectively.

(2a) Compro l'auto nuova, se la lotteria. (vincere) [target: vinco] 'I will buy a new car, if I ___ the lottery.' (win) [target: win]

(2b) Comprerei l'auto nuova, se la lotteria. (vincere) [target: vincessi] 'I would buy a new car, if I the lottery.' (win) [target: won] 


\section{Frequency of verb forms in stimuli}

On the basis of the Corpus of Greek Texts (Goutsos, 2010), the target verb forms of the Greek Mood condition (Task 2) were more frequent than both the target verb forms of the Greek Agreement condition $(\mathrm{t}(77)=-3.313, p=0.001)$ and of the Greek Time Reference condition $(\mathrm{t}(66)=-3.775, p<0.001)($ Task 1). Within the Greek Time Reference condition, the target verb forms of the Past Reference subcondition were more frequent than the target verb forms of the Future Reference subcondition $(\mathrm{t}(22)=2.055, p=0.052)$. There were no other significant differences between (sub)conditions.

On the basis of the $i t W a C$ corpus (Baroni, Bernardini, Ferraresi, \& Zanchetta, 2009), the target verb forms included in the Italian Mood condition (Task 2) were less frequent than the target verb forms of the Italian Time Reference condition (Task 1) ( $\mathrm{t}(59)=-2.515, p=0.015)$ and of the Italian Agreement condition $(\mathrm{t}(60)=2.478, p=0.016)$. In Italian Task 2, the target Indicative forms had a higher frequency of occurrence than the target Subjunctive forms $(\mathrm{t}(29)=-2.684$, $p=0.012$ ). There were no other significant differences between (sub)conditions.

\section{Data analysis}

Results were analyzed at the individual level by means of Fisher's exact test for count data and at the group level by means of generalized mixed-effect regressions, separately for each language (Pinheiro \& Bates, 2000). Unlike traditional analysis of variance (ANOVA), mixed-effect regressions represent the state of the art in linguistic data analysis (e.g., Baayen, 2008; Baayen, Davidson, \& Bates, 2008; Barr, Levy, Scheepers, \& Tily, 2013; Jaeger, 2008), since they allow consideration of the whole structure of data in terms of fixed and random effects, which helps to deal with the "language-as-fixed-effect-fallacy" (Clark, 1973). Another advantage of using mixed-effect models is that they ensure a better statistical power and allow the inclusion of 
covariates in the analyses. Mixed models were fitted using the lme4 package (Bates, Maechler, Bolker, \& Walker, 2014). Because Accuracy was coded as a dichotomous variable (correct or incorrect response at single trial level), generalized mixed models with logit transformation were fitted to the data (Jaeger, 2008). The initial maximal model we tried to fit to our relevant datasets included Accuracy as the dependent variable, Morphosyntactic Condition and Group as fixed effects, Items and Subjects as random effects, the interaction between Morphosyntactic Condition and Group, and Morphosyntactic Condition as by-Subject random slope. The relevant datasets for each language were three: (1) Agreement, Time Reference, and Mood (Dataset 1); (2) Past and Future Reference (Dataset 2); (3) Indicative and Subjunctive Mood (Dataset 3). In both languages, Morphosyntactic Condition had three levels for Dataset 1 (Agreement, Time Reference, Mood), two levels for Dataset 2 (Past Reference, Future Reference), and two levels for Dataset 3 (Indicative Mood, Subjunctive Mood). Group consisted of two levels (Participants with AD, Control participants). Regardless of whether this maximal model converged for a given dataset, we also fitted simpler models (for instance, models without random slopes — see Barr, Levy, Scheepers, \& Tily, 2013) to check which model provided the best fit for each dataset. We used the Akaike Information Criterion (see Burnham \& Anderson, 2004) for model selection. When models including the interaction between Morphosyntactic Condition and Group failed to converge, we first removed the interaction to check if there was a significant difference between the AD group and the control group, and, subsequently, we removed Group from the fixed structure and tried to fit the resulting model to separate datasets for participants with AD and controls. We did so in order to check whether there was a significant difference between the levels of Morphosyntactic Condition in each group. Four best-fitting models for the different datasets were identified: Model 1 included Morphosyntactic Condition and Group as fixed effects, their interaction, and Subjects and Items as random effects. Model 2 included 
Morphosyntactic Condition and Group as fixed effects, and Subjects and Items as random effects. Model 3 included Morphosyntactic Condition as a fixed effect and Subjects and Items as random effects. Model 4 included Morphosyntactic Condition as a fixed effect, Subjects and Items as random effects, and Morphosyntactic Condition as by-Subject random slope.

We also performed Spearman correlation analyses to examine the relationship between MMSE and WM scores, on the one hand, and performance on morphosyntactic categories, on the other hand. Composite WM scores (computed on the basis of the digit ordering span task and the backward digit span task) were used in the correlations. We used Spearman correlation analyses because in all relevant tasks there was non-normal distribution of scores.

\section{RESULTS}

\section{Greek results}

The individual and group results of the Greek participants are given in Table 2. They will be presented and discussed in detail in the following three subsections.

//Insert Table 2 about here//

\section{Greek data: Agreement, Time Reference, Mood}

At the individual level, only four of the 16 Greek-speaking participants with AD (P3, P5, P8, P15) performed within the normal range (that is, within the range of correct performance exhibited by the control group) on all three conditions. Performance outside the normal range on at least one of the three conditions was taken as indication of (selective) impairment. Scrutiny of individual AD data shows that three participants with AD (P6, P13, P14) differ from the others, as they are the only participants who had poor performance $(<61 \%$ correct $)$ on at least one of the 
three categories and exhibited dissociations. They performed worse on Time Reference than on Agreement and Mood (Fisher's exact test; in both comparisons for P6 and P13, $p<0.001$; in both comparisons for P14, $p<0.01$ ), and comparably on Agreement and Mood (see Table 2).

To analyze the results at the group level, we fitted Model 2 to the data of the Greekspeaking participants on Agreement, Time Reference, and Mood. (Model 1 did not converge.) The output of Model 2 showed a significant main effect of Morphosyntactic Condition, with Time Reference being significantly more impaired than Agreement and Mood, and a significant main effect of Group, with control participants performing significantly better than participants with $\mathrm{AD}$ (random intercept for Subjects, $\mathrm{SD}=1.63$; random intercept for Items, $\mathrm{SD}=0.81$; Intercept (Condition=Agreement; Group=AD): $\beta=4.66$, Std. Error $=0.53, z=8.77, p<0.001$; Condition=Mood: $\beta=-0.11$, Std. Error $=0.34, z=-0.32, p=0.748$; Condition=Time Reference: $\beta=-$ 1.82, Std. Error $=0.33, z=-5.50, p<0.001$; Group=Control: $\beta=-3.20$, Std. Error $=0.79, z=4.06$, $p<0.001)$.

To rule out that the main effect of Group resulted entirely from the three participants who had poor performance and exhibited dissociations (P6, P13, P14), we removed them from the Greek dataset and refitted the same model to the new dataset. Again, results showed that the AD group fared significantly worse than the control group (random intercept for Subjects, $\mathrm{SD}=1.11$; random intercept for Items, $\mathrm{SD}=0.86$; Intercept (Condition=Agreement; Group=AD): $\beta=4.80$, Std. Error $=0.52, z=9.16, p<0.001$; Condition=Mood: $\beta=-0.36$, Std. Error $=0.42, z=-0.86, p=0.392$; Condition=Time Reference: $\beta=-0.90$, Std. Error $=0.43, z=-2.07, p=0.038$; Group=Control: $\beta=2.15$, Std. Error $=0.62, z=3.47, p<0.001)$. This is not surprising, as at the group level even small differences can reach significance. Therefore, the between-group difference shown by Model 2 (when fitted to the original dataset) was genuine and not driven by the three "outliers". 
Since we did not manage to fit a model including the interaction between Morphosyntactic Condition and Group, we split the Greek dataset into the dataset of the Greekspeaking participants with $\mathrm{AD}$ and the dataset of the Greek-speaking control participants, and then we fitted Model 3 to the Greek AD dataset. The results of Model 3 showed that the Greekspeaking participants with AD performed worse on Time Reference than on Agreement and Mood (random intercept for Subjects, $\mathrm{SD}=1.58$; random intercept for Items, $\mathrm{SD}=0.72$; Intercept (Condition=Agreement): $\beta=4.52$, Std. Error $=0.52, z=8.73, p<0.001$; Condition=Mood: $\beta=-0.01$, Std. Error $=0.33, z=-0.03, p=0.98$; Condition=Time Reference: $\beta=-1.75$, Std. Error $=0.32, z=-5.48$, $p<0.001)$. It was not possible to successfully fit any model to the Greek controls' dataset, because these participants had ceiling or near-ceiling performance on all conditions. However, a comparison by Fisher's exact test for count data revealed that the Greek control group performed marginally better on Agreement than on Time Reference $(p=0.06)$. Mood did not differ from Agreement or Time Reference.

In order to check if the dissociation observed at the group level was driven by the three participants with AD who showed the most severe impairment and exhibited dissociations (P6, P13, P14), we removed their data from the Greek AD dataset and refitted Model 3 to the new dataset. Without these three participants, dissociations between Agreement, Time Reference, and Mood were no longer present at the group level (random intercept for Subjects, SD=0.94; random intercept for Items, $\mathrm{SD}=0.70$; Intercept (Condition=Agreement): $\beta=4.46$, Std. Error $=0.49, z=9.13$, $p<.001$; Condition=Mood: $\beta=-0.19$, Std. Error $=0.42, z=-0.45, p=0.65$; Condition=Time Reference: $\beta=-0.65$, Std. Error $=0.42, z=-1.53, p=0.125)$.

We also correlated accuracy on Agreement, Time Reference, and Mood with WM and MMSE scores. MMSE was taken as an index of dementia severity. In all cases significant positive correlations were found (Spearman test: WM-Agreement, rho=0.716, $\mathrm{n}=16, p=0.002$; 
WM-Time Reference, $\mathrm{rho}=0.512, \mathrm{n}=16, p=0.042 ; \mathrm{WM}-\mathrm{Mood}, \mathrm{rho}=0.517, \mathrm{n}=16, p=0.040$; MMSE-Agreement, $r h o=0.699, \mathrm{n}=16, p=0.003$; MMSE-Time Reference, $\mathrm{rho}=0.549, \mathrm{n}=16$, $p=0.028 ;$ MMSE-Mood, $\mathrm{rho}=0.675, \mathrm{n}=10, p=0.004)$.

\section{Greek data: Time Reference}

At the individual level, only P6, P13 and P14 exhibited dissociations within Time Reference. They all fared worse on Past Reference than on Future Reference (for P6 and P14, $p<0.001$; for $\mathrm{P} 13, p=0.014)$ (Table 2). Four (P1, P6, P13, P14) and five (P1, P4, P6, P13, P16) Greek-speaking participants with AD performed outside the normal range on Past Reference and Future Reference, respectively.

At the group level, no model including the fixed effect Group was successfully fitted to the Greek Time Reference dataset. We split this dataset into two datasets, one for the participants with $\mathrm{AD}$ and one for the control participants, and fitted Model 4 to the former and Model 3 to the latter. (These were the best-fitting models for these datasets.) Results are presented in Table 3. None of the two groups exhibited dissociations.

Finally, we correlated accuracy on Past Reference and Future Reference with WM and MMSE scores. Only Past Reference was positively and significantly correlated with WM (Spearman test: $\mathrm{rho}=0.526, \mathrm{n}=16, p=0.036$; WM-Future Reference, $\mathrm{rho}=0.168, \mathrm{n}=16, p=0.535$ ). The correlation between MMSE and Past Reference was at the level of a trend (Spearman test: $\mathrm{rho}=0.477, \mathrm{n}=16, p=0.062$ ), and there was no correlation between MMSE and performance on Future Reference (Spearman test: rho $=0.187, \mathrm{n}=16, p=0.487)$.

//Insert Table 3 about here// 


\section{Greek data: Mood}

At the individual level, only P6 exhibited a dissociation - he fared worse on Subjunctive than on Indicative Mood ( $p=0.006)$ (Table 2). Two $(\mathrm{P} 1, \mathrm{P} 6)$ and five (P1, P4, P6, P12, P13) participants with AD performed outside the normal range on Indicative Mood and Subjunctive Mood, respectively.

To analyze the results at the group level, we fitted Model 2 to the Greek dataset for Mood. Results showed significant main effects of Mood, with Indicative Mood eliciting significantly better performance than Subjunctive Mood, and of Group, with controls performing significantly better than participants with $\mathrm{AD}$ (random intercept for Subjects, $\mathrm{SD}=1.76$; random intercept for Items, $\mathrm{SD}=1.01$; Intercept (Condition=Indicative Mood; Group=AD): $\beta=7.17$, Std. Error=1.02, $z=7.00, p<0.001$; Condition=Subjunctive Mood: $\beta=-3.28$, Std. Error $=0.80, z=-4.09, p<0.001$; Group=Control: $\beta=2.69$, Std. Error $=0.98, z=2.74, p=0.006)$.

Since Model 2 did not include the interaction between Mood and Group, we split the Greek dataset for Mood into two datasets, one for the participants with AD and one for the control participants. We tried to fit Model 3 to these datasets, but this only converged for the AD dataset. This was due to the ceiling performance of control participants on both Indicative and Subjunctive Mood. The results of Model 3 for the Greek AD Mood dataset show that, at the group level, participants with AD performed significantly better on Indicative than on Subjunctive Mood (random intercept for Subjects, $\mathrm{SD}=1.55$; random intercept for Items, $\mathrm{SD}=1.02$; Intercept (Condition=Indicative Mood): $\beta=6.97$, Std. Error $=1.01, z=6.94, p<0.001$; Condition=Subjunctive Mood: $\beta=-3.19$, Std. Error $=0.81, z=-3.94, p<0.001)$.

To check if the significant difference between Subjunctive and Indicative Mood at the group level was only driven by P6's performance, we removed his data from the Mood dataset of participants with AD, and refitted Model 3 to the new dataset. Again, Subjunctive was 
significantly more impaired than Indicative (random intercept for Subjects, $\mathrm{SD}=1.29$; random intercept for Items, $\mathrm{SD}=1.32$; Intercept (Condition=Indicative Mood): $\beta=7.55$, Std. Error=1.28, $z=5.88, p<0.001$; Condition=Subjunctive Mood: $\beta=-3.40$, Std. Error $=1.11, z=-3.07, p=0.002$ ).

\section{Italian results}

The individual and group results of the Italian-speaking participants are summarized in Table 4. They will be presented and discussed in detail in the following three subsections.

//Insert Table 4 about here//

\section{Italian data: Agreement, Time Reference, Mood}

At the individual level, seven of the 10 Italian-speaking participants with AD (P2, P4, P6, P7, P8, P9, P10) performed outside the normal range on at least one category (see Table 4). Of the eight participants with $\mathrm{AD}$ who completed both tasks, only P1 did not show dissociation between Agreement, Time Reference, and Mood. Of the seven participants with AD who exhibited dissociations, five (P3, P4, P5, P7, P9) performed better on Agreement and Time Reference than on Mood (in P3, P4, P5, P7, for all comparisons by Fisher's exact test, $p<0.001$ or $p<0.01$; in P9, Agreement vs. Mood: $p=0.05$; Time Reference vs. Mood: $p<0.001)$. P9 also performed worse on Agreement than on Time Reference $(p=0.05)$. The remaining two participants with AD, P6 and P10, performed better on Agreement than on Time Reference and Mood (for both participants, in all comparisons by Fisher's exact test, $p<0.001$ or $p<0.01$ or $p=0.01$ ).

To analyze the results at the group level, we fitted Model 1 to the "Agreement, Time Reference, and Mood dataset" of the Italian-speaking participants. Results are shown in Table 5. (Note that we added a random error in the control participants' results on Time Reference in 
order to improve the model fit capability. For a similar approach with similar kind of data, see Varkanitsa et al., 2016.) There was a main effect of Group, with control participants outperforming participants with AD, and a main effect of Morphosyntactic Condition, with Agreement yielding better performance than Time Reference and Mood, and Time Reference yielding better performance than Mood. (To compare Time Reference with Mood, we re-fitted Model 1 with Mood as reference. Time Reference elicited better performance than Mood at $p<0.001)$. The interaction between Morphosyntactic Condition and Group was significant. Although in both groups Agreement and Time Reference were better preserved than Mood, the $\mathrm{AD}$ and the control groups exhibited Agreement-Time Reference dissociations in opposite directions (AD group: Agreement>Time Reference; Control group: Agreement $<$ Time Reference).

We also correlated accuracy on Agreement, Time Reference, and Mood with WM scores and MMSE scores (dementia severity). In all cases there were positive correlations, but none reached significance (Spearman test: $\mathrm{WM}-$ Agreement, $\mathrm{rho}=0.550, \mathrm{n}=8, p=0.158$; WM-Time Reference, $\mathrm{rho}=0.441, \mathrm{n}=8, p=0.274 ; \mathrm{WM}-\mathrm{Mood}, \mathrm{rho}=0.379, \mathrm{n}=10, p=0.281$; MMEAgreement, $\mathrm{rho}=0.509, \mathrm{n}=8, p=0.197$; MMSE-Time Reference, $\mathrm{rho}=0.589, \mathrm{n}=8, p=0.125$; MMSE-Mood, $\mathrm{rho}=0.53, \mathrm{n}=10, p=0.114)$.

//Insert Table 5 about here//

\section{Italian data: Time Reference}

At the individual level, of the eight Italian-speaking participants with $\mathrm{AD}$ who completed the relevant task, only one (P6) exhibited a dissociation. He performed worse on Past Reference than 
on Future Reference $(p<0.001)$. Four (P4, P6, P7, P10) and three (P6, P7, P10) participants with AD performed outside the normal range on Past and Future Reference, respectively (see Table 4). At the group level, no model including Group as a fixed effect was successfully fitted to the Time Reference dataset of the Italian-speaking participants. Thus, we split it into two datasets, one for the participants with $\mathrm{AD}$ and one for the control participants. The best-fitting model for the AD dataset was Model 4. No model fitted to the dataset of the control group converged, because these participants performed at ceiling on both Past and Future Reference. The results of Model 4 for the Time Reference dataset of the Italian-speaking participants with AD show that these participants fared comparably on Past and Future Reference (random intercept for Subjects, $\mathrm{SD}=5.86$; random intercept for Items, $\mathrm{SD}=0.54$; Intercept (Condition=Future Reference): $\beta=7.17$, Std. Error $=4.13, z=1.74, p=0.083$; Condition=Past Reference: $\beta=-2.99$, Std. Error $=3.25, z=-0.92, p=0.357$; see also total results for Time Reference in Table 4).

We also correlated accuracy on Past Reference and Future Reference with WM and MMSE scores. In all cases there were positive correlations, with the exception of WM-Future Reference, where no correlation emerged. However, none of these correlations were significant. (WM-Past Reference, $\mathrm{rho}=0.507, \mathrm{n}=8, p=0.2 ; \mathrm{WM}-$ Future Reference, $\mathrm{rho}=0.099, \mathrm{n}=8, p=0.815$; MMSE-Past Reference, rho=0.562, $\mathrm{n}=8, p=0.147$; MMSE-Future Reference, rho=0.647; $\mathrm{n}=8$, $p=0.083)$.

\section{Italian data: Mood}

At the individual level (Table 4), of the 10 participants with AD who completed the relevant task, six exhibited dissociations between Indicative and Subjunctive Mood. Five participants with AD (P2, P3, P4, P6, P9) fared better on Indicative than on Subjunctive (Fisher's exact test; for P2 and 
$\mathrm{P} 3, p<0.001$; for $\mathrm{P} 4$ and $\mathrm{P} 9, p=0.01$; for $\mathrm{P} 6, p=0.029$ ) and one (P5) exhibited the opposite pattern $(p<0.001)$. One (P7) and seven (P2, P3, P4, P6, P7, P9, P10) participants with AD performed outside the normal range on the Indicative Mood and Subjunctive Mood, respectively.

To analyse the results at the group level, we fitted Model 1 to the Italian Mood dataset. The results are presented in Table 6. There were significant main effects of Group, with participants with AD performing worse than controls, and of Mood, with Indicative eliciting a significantly better performance than Subjunctive.

//Insert Table 6 about here//

\section{DISCUSSION}

The aim of this study, which was a follow-up on Fyndanis et al. (2013), was to investigate whether verb-related morphosyntactic production is impaired in Greek- and Italian-speaking individuals with AD and whether the IFIH (e.g., Fyndanis et al., 2012) and the PADILIH (Bastiaanse et al., 2011), recent hypotheses originally developed in aphasia research, can also capture results related to $\mathrm{AD}$. The IFIH states that categories requiring integration of information from two distinct levels of representation (conceptual/extra-linguistic and grammatical), such as Time Reference and Mood, are more demanding in terms of processing resources than categories that do not involve integration processes, such as Agreement. The PADILIH posits that reference to the past is more demanding than reference to the present or future, because reference to the past involves discourse linking. This is not the case with reference to the present/future (Zagona, 2003, 2013). The morphosyntactic categories explored were Agreement, Time Reference, and Mood. The Time Reference condition consisted of two subconditions: Past Reference and Future 
Reference. The study also explored the relationship between verbal WM and severity of dementia, on the one hand, and morphosyntactic production, on the other hand.

Both the Greek and Italian results indicate that the production of verb-related morphosyntactic categories can be impaired in mild-to-moderate AD. Only four out of 16 Greekspeaking participants with $\mathrm{AD}(\mathrm{P} 3, \mathrm{P} 5, \mathrm{P} 8, \mathrm{P} 15)$ and three out of 10 Italian-speaking participants with $\mathrm{AD}(\mathrm{P} 1, \mathrm{P} 3, \mathrm{P} 5)$ performed within the normal range on all three conditions (Agreement, Time Reference, Mood). However, while half of the Italian-speaking participants with AD (P2, P6, P7, P8, P10) showed severe morphosyntactic impairment (3-55\% correct performance on at least one of the three categories), only three of the 16 Greek-speaking participants with AD (P6, P13, P14) were severely impaired (30-60\% correct performance on Time Reference). That not all individuals with AD had a morphosyntactic impairment is consistent with Altmann et al. (2001), who found that only three of their 10 English-speaking participants with AD had an agrammatic profile. The results are also in line with Fyndanis et al. (2013), who reported agrammatic patterns for their Greek-speaking participants with AD, and with Sajjadi et al. (2012), who reported more verb inflection errors for their participants with AD compared to controls. They contrast with the view that morphosyntactic production is generally preserved in mild-to-moderate AD (e.g., Blanken et al., 1987; Kavé \& Levy, 2003; Kempler et al., 1987).

Although the positive correlations between MMSE and the three impaired morphosyntactic categories in the two AD groups (significant for the Greek group and not for the Italian group) suggest that dementia severity may contribute to morphosyntactic impairment in $\mathrm{AD}$, the fact that morphosyntactic production was more impaired in the Italian than in the Greek group cannot be accounted for in terms of severity of dementia. This is so because the Greek AD group was cognitively more impaired than the Italian AD group. Worse performance of the Italian $\mathrm{AD}$ group cannot be accounted for in terms of WM, education or age either, because all 
three were comparable in the two groups. Instead, better performance on morphosyntactic production in the Greek AD group, as compared to the Italian AD group, could be partly accounted for by the language-specific properties of the morphosyntactic phenomena under consideration here. We will return to this issue later in this section.

Selective deficits were observed in three of the 16 Greek-speaking participants with AD (P6, P13, P14) and in seven out of eight Italian-speaking participants with AD who completed both tasks (P3, P4, P5, P6, P7, P9, P10). The selectivity of the morphosyntactic deficit was also reflected in the performance of the Greek- and Italian-speaking participants with AD at the group level (Greek AD group: Agreement/Mood>Time Reference; Italian AD group: Agreement>Time Reference $>$ Mood). This is consistent with Fyndanis et al. (2013). However, the dissociation observed at the group level for the Greek-speaking participants with AD was only driven by the three participants who exhibited dissociations (P6, P13, P14), suggesting that the Greek group results are not robust. The pattern of performance exhibited by the Greek-speaking participants with AD can be only in part accounted for by the IFIH (Fyndanis et al., 2012), which does not agree with Fyndanis et al.'s (2013) main findings. According to this hypothesis, Agreement is easier to process than Time Reference and Mood, because it requires implementation of grammatical knowledge only. In contrast, to produce Time Reference and Mood, one has to process and integrate grammatical and extra-linguistic/conceptual information. Thus, while the Agreement-Time Reference dissociation observed in the Greek AD group is consistent with the IFIH, this hypothesis would not predict Mood to be as preserved as Agreement. The better performance on Agreement than on Time Reference and Mood in the Italian AD group is consistent with the IFIH.

Part of the Greek and Italian data can be explained in terms of frequency. The lack of dissociation between Agreement and Mood in the Greek AD group could be attributed to the fact 
that the target verb forms of the Mood condition were more frequent than the target verb forms of the Agreement condition. According to this assumption, the frequency effect is stronger than the demands associated with the integration processes that Mood involves, and thus the frequency advantage overrides the disadvantage associated with the involvement of integration processes. In the same vein, the better performance on Mood than on Time Reference may be due to the higher frequency of the target verb forms of the Mood condition. As far as the Italian AD group is concerned, the worse performance on Mood than on Time Reference could be due to the lower frequency of the target verb forms of the Mood condition.

It is important to note, however, that the dissociation between Agreement and Time Reference, found in both the Greek and Italian AD groups, cannot be accounted for in terms of frequency, because the target verb forms included in the two conditions did not differ in mean frequency. Frequency, thus, cannot account for all patterns reported here. Instead, a parsimonious account for the present cross-linguistic data is to assume that the scope of IFIH is narrower than was originally proposed. According to this account, IFIH's predictions apply only to categories involving bound morphology (or, alternatively termed, inflectional alternations). Recall that Agreement, Time Reference, and both Indicative and Subjunctive Mood involve inflectional alternations in Italian. This is not the case with the Subjunctive Mood in Greek, since its markers are free-standing morphemes.

Hence, the different patterns observed in Greek and Italian may be partly due to the different ways these two languages encode Mood. In the context of the present study, it was the free-standing morpheme $n a$ that always marked the Subjunctive Mood. The marker na usually follows specific types of verbs (e.g., volition verbs) that subcategorize for Subjunctive Mood. In the task used to test Mood in Greek, the production of the Subjunctive Mood marker (na) was triggered by the presence of the volition verb $\theta e ́ l o$ "to want". Participants' high performance in 
this task probably reflects their intact (lexical) knowledge of the subcategorization properties of volition verbs. Mood in Italian is marked on the verb by means of inflectional morphology or allomorph retrieval. In the Italian task tapping Mood, based on the Mood value of the verb in the matrix clause, participants had to retrieve a finite verb form that encoded either the Subjunctive or Indicative Mood. Therefore, although the two language versions of Task 2 tested Mood, they differed in that the Greek task did not require retrieval of specific inflectional verbal morphemes or verb forms, whereas the Italian task did. The results, thus, suggest that the language-specific properties of (morpho)syntactic categories matter. This is in line with the findings of Bencini et al. (2011), who showed that sentence repetition patterns in AD depend on the structural properties of a given language.

The fact that WM scores were positively correlated with Agreement, Time Reference and Mood in both languages suggests that verbal WM contributes to verb-related morphosyntactic production. Positive correlations were significant only for the Greek AD group possibly because of the smaller number of Italian-speaking participants with $\mathrm{AD}(\mathrm{N}=10)$. However, WM does not appear to affect Agreement, Time Reference and Mood differentially, which suggests that the dissociations between the three categories are not due to WM limitations. It may be the case that these dissociations stem from limitations in a different cognitive domain, such as inhibition. In the context of this study, inhibition was always involved as the participant had to avoid repeating the verb form that appeared in the source sentence. Future research should address this issue.

The individual data of the Greek- and Italian-speaking participants with AD are consistent with the PADILIH (Bastiaanse et al., 2011), as all four participants with AD who showed dissociation between Past and Future Reference (P6, P13, P14 of the Greek group, and P6 of the Italian group) exhibited the pattern predicted by this hypothesis (Past Reference $<$ Future Reference). At the group level, however, dissociations did not emerge in any of the two 
languages, which is in line with Fyndanis et al.'s (2013) results. Hence, the support our study lends to the PADILIH is rather limited. On the other hand, the significant interaction between WM and Time Reference that was observed in the Greek AD group is consistent with the PADILIH, as WM affected performance on Past Reference but not on Future Reference. This finding is also consistent with the idea that the processing resources required for the production of verb forms referring to different time frames is closely related to verbal WM. The absence of a significant positive correlation between WM and Past Reference in the Italian AD group may be due to the small sample size. Therefore, the PADILIH should be further tested with larger cohorts of participants with AD.

It is worth mentioning that at the group level, in both languages, participants with $\mathrm{AD}$ and controls showed the same or similar patterns of performance (Greek AD group: Agreement/Mood>Time Reference; Greek control group: Agreement>Time Reference \& Agreement $=$ Mood \& Time Reference $=$ Mood; Italian AD group: Agreement $>$ Time Reference $>$ Mood; Italian control group: Time Reference $>$ Agreement $>$ Mood). This finding suggests that, at least in $\mathrm{AD}$, normal and pathological performance on verb-related morphosyntactic production partly lies on a continuum in that pathology exacerbates language behavior observed in neurologically intact speakers (e.g., Dick et al., 2001; Miyake, Carpenter, \& Just, 1994). Therefore, the observed patterns of performance at the group level do not seem to be specific to AD pathology. These patterns can be attributed to inherent differences of Agreement, Time Reference and Mood in processing load in Greek and Italian. The within language heterogeneity, however, is also consistent with the possibility that the way neurodegenerative disease affects specific linguistic processes differs across participants. For instance, in the Italian AD group, two participants (P6, P10) performed better on Agreement than on Time Reference, and one (P9) exhibited the opposite pattern. 
The within language comparison between Indicative and Subjunctive Mood showed that the former is easier than the latter in both $\mathrm{AD}$ groups, which is consistent with the view that unmarked values are easier to process than marked ones (Lapointe, 1985). The better performance of the Italian AD group on the Indicative Mood as compared to the Subjunctive Mood could also be explained in terms of frequency, since the target Indicative forms had a higher frequency of occurrence than the target Subjunctive forms. Interestingly, a double dissociation emerged within the Italian AD group: five participants (P2, P3, P4, P6, P9) performed better on the Indicative than on the Subjunctive Mood and one (P5) exhibited the opposite pattern. This double dissociation is likely due to a cognitive strategy employed by P5, who tended to resort to the "demanding" (marked) Mood value, that is, Subjunctive Mood. Being aware of the fact that a given condition is the most demanding, participants with AD like P5 may try to produce verb forms that instantiate that category even when this is not needed, which leads to overgeneralization errors.

To summarize, the main conclusions that one can draw from the results are the following:

(1) Speakers with mild-to-moderate AD may have impairments in morphosyntactic production.

(2) Dementia severity is not the only factor that determines the incidence of morphosyntactic deficits in mild-to-moderate $\mathrm{AD}$, and WM only partially accounts for results.

(3) As far as morphosyntactic production is concerned, although participants with (mild-tomoderate) AD perform worse than healthy controls, both cohorts exhibit similar patterns of performance. This suggests that the patterns of morphosyntactic impairment in AD are not shaped by the AD pathology but by other factors.

(4) At the group level, the patterns of performance are not consistent across languages but appear to be partly determined by language-specific properties. Frequency (of target verb 
forms in constrained tasks) may also modulate morphosyntactic performance.

(5) Recent hypotheses proposed for agrammatic aphasia, namely the IFIH (Fyndanis et al., 2012) and the PADILIH (Bastiaanse et al., 2011), cannot account for the cross-linguistic AD patterns of morphosyntactic production that emerge at the group level.

(6) However, as shown in this study, the IFIH can be informed by cross-linguistic data and modified accordingly, so that it can capture cross-linguistic patterns. Specifically, it is suggested that morphosyntactic categories that involve integration processes are harder to process than those that do not, unless they are instantiated through free-standing morphemes.

(7) Moreover, the PADILIH is consistent with the cross-linguistic individual data reported here, as all four participants with $\mathrm{AD}$ who exhibited within-Time Reference dissociations fared worse on Past Reference than on Future Reference. The interaction found between WM and Time Reference is also consistent with the PADILIH.

(8) Neurodegenerative disease can affect specific linguistic processes differentially across participants.

A limitation of the study pertains to the relatively small number of Greek $(\mathrm{N}=16)$ and Italian $(\mathrm{N}=10)$ participants with $\mathrm{AD}$. The fact that no significant correlations (between WM and MMSE scores, on the one hand, and performance on the three morphosyntactic categories, on the other hand) emerged in the Italian AD group could be the result of sample size. Furthermore, the dissociations between Agreement, Time Reference and Mood that emerged at the group level for the Greek-speaking participants with $\mathrm{AD}$ were only driven by three participants, indicating that these dissociations are not robust.

We plan to carry out further similar investigations where we will test larger cohorts of individuals with $\mathrm{AD}$-ideally cohorts consisting of equal numbers of participants with mild AD 
and participants with moderate AD- with more cognitive tasks that will tap not only verbal WM but also executive functions such as inhibition. Such investigations will allow us to check if the same dissociations emerge when testing a larger number of participants with $\mathrm{AD}$, as well as to explore the role of other cognitive systems and potentially relevant factors, such as stage of AD and education. Future research should also test the hypothesis that the IFIH's predictions only apply to categories involving inflectional alternations by investigating more morphosyntactic categories that involve integration processes but do not involve inflectional alternations, such as sentential Negation.

\section{Acknowledgments}

This research was supported by a Marie Curie Intra European Fellowship (awarded to the first author) within the $7^{\text {th }}$ European Community Framework Programme, project reference 329795 , and by the Research Council of Norway through its Centres of Excellence funding scheme, project number 223265 .

We are grateful to all individuals who took part in this study. We also thank Fabiana Galiussi for helping with data transcription, the Guest Editor of this Special Issue, Carol Leonard, three anonymous reviewers, and Hanne Gram Simonsen, Ruggerro Bellio, Athanassios Protopapas, Charalambos Themistokleous, Maria Varkanitsa, Francesca Franzon and Chiara Zanini for their useful comments and suggestions.

\section{REFERENCES}

Almor, A., Aronoff, J. M., MacDonald, M. C., Gonnerman, L. M., Kempler, D., Hintiryan, H., Hayes, U. L., Arunachalam, S., \& Andersen, E. S. (2009). A common mechanism in verb and noun naming deficits in Alzheimer's patients. Brain and Language, 111, 8-19. doi: 
10.1016/j.bandl.2009.07.009

Altmann, L. J. P. (2004). Constrained sentence production in probable Alzheimer disease. Applied Psycholinguistics, 25, 145-173. doi: 10.1017.S0142716404001080

Altmann, L. J. P., Kempler, D., \& Andersen, E. S. (2001). Speech errors in Alzheimer's disease: Reevaluating morphosyntactic preservation. Journal of Speech, Language, and Hearing Research, 44, 1069-1082. doi: 10.1044/1092-4388(2001/085

Aronoff, J. M., Gonnerman, L. M., Almor, A., Arunachalam, S., Kempler, D., \& Andersen, E. S. (2006). Information content versus relational knowledge: Semantic deficits in patients with Alzheimer's disease. Neuropsychologia, 44, 21-35. doi: 10.1016/j.neuropsychologia.2005.04.014

Auclair-Ouellet, N. (2015). Inflectional morphology in primary progressive aphasia and Alzheimer's disease: A systematic review. Journal of Neurolinguistics, 34, 41-64. doi: 10.1016/j.jneuroling.2014.12.002

Baayen, R. H. (2008). Analyzing linguistic data: A practical introduction to statistics using $R$. New York: Cambridge University Press.

Baayen, R. H., Davidson, D. J., \& Bates, D. M. (2008). Mixed-effects modeling with crossed random effects for subjects and items. Journal of Memory and Language, 59, 390-412. doi: $10.1016 /$ j.jml.2007.12.005

Baddeley, A. (1992). Working memory. Science, 255, 556-559. doi:10.1126/science.1736359

Baddeley, A. (1996). Exploring the central executive. The Quarterly Journal of Experimental Psychology, 49, 5-28. doi: 10.1080/713755608

Baddeley, A. D., Bressi, S., Della Sala, S., Logie, R., \& Spinnler, H. (1991). The decline of working memory in Alzheimer's disease. Brain, 114, 2521-2542. doi: 


\subsection{3/brain/114.6.2521}

Baroni, M., Bernardini, S., Ferraresi, A., \& Zanchetta, E. (2009). The WaCky Wide Web: A collection of very large linguistically processed web-crawled corpora. Language Resources \& Evaluation, 43, 209. doi:10.1007/s10579-009-9081-4

Barr, D. J., Levy, R., Scheepers, C., \& Tily, H. J. (2013). Random effects structure for confirmatory hypothesis testing: Keep it maximal. Journal of Memory and Language, 68, 255-278. doi: 10.1016/j.jml.2012.11.001

Bastiaanse, R., Bamyaci, E., Hsu, C., Lee, J., Yarbay Duman, T., \& Thompson, C. K. (2011). Time reference in agrammatic aphasia: A cross-linguistic study. Journal of Neurolinguistics, 24, 652-673. doi: 10.1016/j.jneuroling.2011.07.001

Bates, D., Maechler, M., Bolker, B., \& Walker, S. (2014). lme4: Linear mixed-effects models using Eigen and S4. R package version 1.1-6. http://CRAN.R-project.org/package=lme4

Becker, J. T., \& Overman, A. A. (2002). The memory deficit in Alzheimer's disease. In A. D. Baddeley, M. D. Kopelman, \& B. A. Wilson (Eds.), The handbook of memory disorders (2nd ed., pp. 569-589). Chichester: John Wiley \& Sons.

Bencini, G. M. L., Pozzan, L., Biundo, R., McGeown, W. J., Valian, V. V., Venneri, A., \& Semenza, C. (2011). Language-specific effects in Alzheimer's disease: Subject omission in Italian and English. Journal of Neurolinguistics, 24, 25-40. doi: 10.1016/j.jneuroling.2010.07.004

Blanken, G., Dittman, J., Haas, J.-C., \& Wallesch, C.-W. (1987). Spontaneous speech in senile dementia and aphasia: Implications for a neurolinguistic model of language production. Cognition, 27, 247-274. doi: 10.1016/S0010-0277(87)80011-2

Bowles, N. L., Obler, L. K., \& Albert, M. L. (1987). Naming errors in healthy aging and 
dementia of the Alzheimer type. Cortex, 23, 519-524. doi: 10.1016/S00109452(87)80012-6

Burnham, K. P., \& Anderson, D. R. (2004). Multimodel inference: Understanding AIC and BIC in model selection. Sociological Methods and Research, 33, 261-304. doi: $10.1177 / 0049124104268644$

Chomsky, N. (1995). The Minimalist Program. Cambridge, MA: MIT Press.

Chomsky, N. (2000). Minimalist inquiries: The framework. In R. Martin, D. Michaels, and J. Uriagereka (Eds.), Step by Step (pp. 89-155). Cambridge, MA: MIT Press.

Chomsky, N. (2001). Derivation by phase. In K. Kenstowicz (Ed.), Ken Hale: A Life in Language (pp. 1-52). Cambridge, MA: MIT Press.

Clark, H. H. (1973). The language-as-fixed-effect fallacy: A critique of language statistics in psychological research. Journal of Verbal Learning and Verbal Behavior, 12, 335-359.

Collette, F., Van der Linden, M., Bechet, S., \& Salmon, E. (1999). Phonological loop and central executive functioning in Alzheimer's disease. Neuropsychologia, 37, 905-918. doi: $10.1016 / \mathrm{S} 0028-3932(98) 00148-1$

Colombo, L., Fonti, C., \& Stracciari, A. (2009). Italian verb inflection in Alzheimer dementia. Neuropsychologia, 47, 1069-1078. doi: 10.1016/j.neuropsychologia.2008.12.035

Cortese, M. J., Balota, D. A., Sergent-Marshall, S. D., Buckner, R. L., \& Gold, B. T. (2006). Consistency and regularity in past-tense verb generation in healthy ageing, Alzheimer's disease, and semantic dementia. Cognitive Neuropsychology, 23, 856-876. doi: $10.1080 / 02643290500483124$

Dick, F., Bates, E., Wulfeck, B., Utman, J. A., Dronkers, N., \& Gernsbacher, M. A. (2001). 
Language deficits, localization, and grammar: Evidence for a distributive model of language breakdown in aphasic patients and neurologically intact individuals. Psychological Review, 108, 759-788. doi: 10.1037/0033-295X.108.4.759

Druks, J., Masterson, J., Kopelman, M., Clare, L., Rose, A., \& Rai, G. (2006). Is action naming better preserved (than object naming) in Alzheimer's disease and why should we ask? Brain and Language, 98, 332-340. doi: 10.1016/j.bandl.2006.06.003

Folstein, M., Folstein, S., \& McHugh, P. R. (1975). Mini Mental State: A practical method for grading the cognitive state of patients for the clinician. Journal of Psychiatric Research, 12, 189-198. doi: 10.1016/0022-3956(75)90026-6

Friedmann, N., \& Grodzinsky, Y. (1997). Tense and agreement in agrammatic production: Pruning the syntactic tree. Brain and Language, 56, 397-425. doi: 10.1006/brln.1997.1795

Fyndanis, V., Manouilidou, C., Koufou, E., Karampekios, S., \& Tsapakis, E. M. (2013). Agrammatic patterns in Alzheimer's disease: Evidence from tense, agreement, and aspect. Aphasiology, 27, 178-200. doi: 10.1080/02687038.2012.705814

Fyndanis, V., Varlokosta, S., \& Tsapkini, K. (2012). Agrammatic production: Interpretable features and selective impairment in verb inflection. Lingua, 122, 1134-1147. doi: 10.1016/j.lingua.2012.05.004

Goutsos, D. (2010). The Corpus of Greek Texts: A reference corpus for Modern Greek. Corpora 5, 29-44. doi: 10.3366/cor.2010.0002

Harciarek, M., \& Kertesz, A. (2009). Longitudinal study of single-word comprehension in semantic dementia: A comparison with primary progressive aphasia and Alzheimer's disease. Aphasiology, 23, 606-626. doi: 10.1080/02687030801890891 
Hodges, J. R., \& Patterson, K. (1995). Is semantic memory consistently impaired early in the course of Alzheimer's disease? Neuroanatomical and diagnostic implications. Neuropsychologia, 33, 441-460. doi: 10.1016/0028-3932(94)00127-B

Holton, D., Mackridge, P., \& Philippaki-Warburton, I. (1997). Greek: A Comprehensive Grammar of the Modern Language. London/New York: Routledge.

Jaeger, T. F. (2008). Categorical data analysis: Away from ANOVAs (transformation or not) and towards logit mixed models. Journal of Memory and Language, 59, 434-446. doi: 10.1016/j.jml.2007.11.007

Kavé, G., \& Levy, Y. (2003). Morphology in picture descriptions provided by persons with Alzheimer's disease. Journal of Speech, Language, and Hearing Research, 46, 341-352. doi: $10.1044 / 1092-4388(2003 / 027)$

Kemper, S., LaBarge, E., Ferraro, F. R., Cheung, H., \& Storandt, M. (1993). On the preservation of syntax in Alzheimer's disease. Evidence from written sentences. Archives of Neurology, 50, 81-86. doi: 10.1001/archneur.1993.00540010075021

Kempler, D., Curtiss, S., \& Jackson, C. (1987). Syntactic preservation in Alzheimer's disease. Journal of Speech and Hearing Research, 30, 343-350. doi: $10.1044 /$ jshr.3003.343

Kempler, D. (2005). Neurocognitive Disorders in Aging. Thousand Oaks: Sage Publications. Kempler, D., Almor, A., Tyler, L. K., Andersen, E. S., \& MacDonald, M. C. (1998). Sentence comprehension deficits in Alzheimer's Disease: A comparison of off-line vs. online sentence processing. Brain and Language, 64, 297-316. doi: 10.1006/brln.1998.1980

Kempler, D., Andersen, E. S., \& Henderson, V. W. (1995). Linguistic and attentional contributions to anomia in Alzheimer's disease. Neuropsychiatry, Neuropsychology, and 
Behavioral Neurology, 8, 33-37.

Kempler, D., Almor, A., MacDonald, M., \& Andersen, E. (1999). Working with limited memory: Sentence comprehension in Alzheimer's disease. In S. Kemper \& R. Kliegl (Eds.), Constraints on language: Aging, grammar, and memory (pp. 227-246). Boston: Kluwer Academic Publishers.

Kensinger, E. A., Shearer, D. K., Locascio, J. J., Growdon, J. H., \& Corkin, S. (2003). Working memory in mild Alzheimer's disease and early Parkinson's disease. Neuropsychology, 17, 230-239. doi: 10.1037/0894-4105.17.2.230

Kim, M., \& Thompson, C. K. (2004). Verb deficits in Alzheimer's disease and agrammatism: Implications for lexical organisation. Brain and Language, 88, 1-20. doi: 10.1016/S0093934X(03)00147-0

Kok, P., van Doorn, A., \& Kolk, H. (2007). Inflection and computational load in agrammatic speech. Brain and Language, 102, 273-283. doi: 10.1016/j.band1.2007.03.001

Lapointe, S. G. (1985). A theory of verb form use in the speech of agrammatic aphasics. Brain and Language, 24, 100-155. doi: 10.1016/0093-934X(85)90100-2

MacDonald, M. C., Almor, A., Henderson, V. W., Kempler, D., \& Andersen, E. S. (2001). Assessing working memory and language comprehension in Alzheimer's disease. Brain and Language, 78, 17-42. doi: 10.1006/brln.2000.2436

Masterson, J., Druks, J., Kopelman, M., Clare, L., Garley, C., \& Hayes, M. (2007). Selective naming (and comprehension) deficits in Alzheimer's disease? Cortex, 43, 921-934. doi: 10.1016/S0010-9452(08)70691-9

McKhann, G., Drachman, D., Folstein, M., Katzman, R., Price, D., \& Stadian, E. M. (1984). Clinical diagnosis of Alzheimer's disease: Report on the NINCDS-ADRDA work group under the auspices of the Department of Health and Human Services Task Force on 
Alzheimer's disease. Neurology, 34, 939-944. doi: 10.1212/WNL.34.7.939

McKhann, G. M., Knopman, D. S., Chertkow, H., Hyman, B. T., Jack Jr., C. R., Kawas, C. H., Klunk, W. E., Koroshetz, W. J., Manly, J. J., Mayeux, R., Mohs, R. C., Morris, J. C., Rossor, M. N., Scheltens, P., Carrillo, M. C., Thies, B., Weintraub, S., \& Phelps, C. H. (2011). The diagnosis of dementia due to Alzheimer's disease: Recommendations from the National Institute on Aging-Alzheimer's Association workgroups on diagnostic guidelines for Alzheimer's disease. Alzheimer's \& Dementia, 7, 263-269. doi: 10.1016/j.jalz.2011.03.005

Miyake, A., Carpenter, P. A., \& Just, M. (1994). A capacity approach to syntactic comprehension disorders: Making normal adults perform like aphasic patients. Cognitive Neuropsychology, 11, 671-717. doi: 10.1080/02643299408251989

Morris, R. G., \& Baddeley, A. D. (1988). Primary and working memory functioning in Alzheimer- type dementia. Journal of Clinical and Experimental Neuropsychology, 10, 279-296. doi: 10.1080/ 01688638808408242

Nanousi, V., Masterson, J., Druks, J., \& Atkinson, M. (2006). Interpretable vs. uninterpretable features: Evidence from six Greek-speaking agrammatic patients. Journal of Neurolinguistics, 19, 209-238. doi: 10.1016/j.jneuroling.2005.11.003

Pinheiro, J. C., \& Bates, D. M. (2000). Mixed-effects models in S and S-PLUS, Statistics and Computing. New York: Springer.

Radford, A. (2004). Minimalist Syntax: Exploring the Structure of English. Cambridge: Cambridge University Press.

Ralli, A. (1988). Eléments de la morphologie du Grec Moderne: La structure du verbe. Unpublished doctoral dissertation. Université de Montréal, Montreal, Canada. 
Robinson, K. M., Grossman, M., White-Devine, T., \& D’Esposito, M. (1996). Category-specific difficulty naming with verbs in Alzheimer's disease. Neurology, 47, 178-182. doi: 10. 1212/WNL.47.1.178 0.1212/WNL.47.1.178

Rochon, E., Waters, G. S., \& Caplan, D. (1994). Sentence comprehension in patients with Alzheimer's disease. Brain and Language, 46, 329-349. doi: 10.1006/brln.1994.1018

Rochon, E., Waters, G. S., \& Caplan, D. (2000). The relationship between measures of working memory and sentence comprehension in patients with Alzheimer's disease. Journal of Speech, Language, and Hearing Research, 43, 395-414. doi: 10.1044/jslhr.4302.395

Rofes, A., Bastiaanse, R., \& Martínez-Ferreiro, S. (2014). Conditional and future tense impairment in non-fluent aphasia, Aphasiology, 28, 99-

115. doi: $10.1080 / 02687038.2013 .850650$

Sajjadi, S. A., Patterson, K., Tomek, M., \& Nestor, P. J. (2012). Abnormalities of connected speech in semantic dementia vs Alzheimer's disease. Aphasiology, 26, 847-866. doi: $10.1080 / 02687038.2012 .654933$

Stavrakaki, S., \& Kouvava, S. (2003). Functional categories in agrammatism: Evidence from Greek. Brain and Language, 86, 129-141. doi: 10.1016/S0093-934X(02)00541-2

Ullman, M. T., Corkin, S., Coppola, M., Hickok, G., Growdon, J. H., Koroshetz, W. J., \& Pinker, S. (1997). A neural dissociation within language: Evidence that the mental dictionary is part of declarative memory, and that grammatical rules are processed by the procedural system. Journal of Cognitive Neuroscience, 9, 266-276. doi: 10.1162/jocn.1997.9.2.266

Varkanitsa, M., Kasselimis, D., Fugard, A. J. B., Evdokimidis, I., Druks, J., Potagas, C., \& Van de Koot, H. (2016). Syntactic predictions and asyntactic comprehension in aphasia: Evidence from scope relations. Journal of Neurolinguistics, 40, 15-36. doi: 10.1016/j.jneuroling.2016.04.001 
Varlokosta, S., Valeonti, N., Kakavoulia, M., Lazaridou, M., Economou, A., \& Protopapas, A., (2006). The breakdown of functional categories in Greek aphasia: Evidence from agreement, tense, and aspect. Aphasiology, 20, 723-743. doi:

$10.1080 / 02687030500513703$

Walenski, M., Sosta, K., Cappa, S., \& Ullman, M. T. (2009). Deficits on irregular verbal morphology in Italian-speaking Alzheimer's disease patients. Neuropsychologia, 47, 1245-1255. doi: 10.1016/j.neuropsychologia.2008.12.038

Warburton, I. (1973). Modern Greek verb conjugation: Inflectional morphology in a transformational grammar. Lingua, 32, 193-226. doi: 10.1016/0024-3841(73)90042-9

Waters, G. \& Caplan, D. (2002). Working memory and online syntactic processing in Alzheimer's disease: Studies with auditory moving window presentation. Journal of Gerontology: Psychological Sciences, 57B, P298-P311. doi: 10.1093/geronb/57.4.P298

Waters, G. S., \& Caplan, D. (2003). The reliability and stability of verbal working memory measures. Behavior Research Methods, Instruments, \& Computers, 35, 550564. doi: 10.3758/BF03195534

Whatmough, C., \& Chertkow, H. (2002). Category-specific recognition impairments in Alzheimer's disease. In E. M. E. Forde \& G. W. Humphreys (Eds.), Category specificity in brain and mind (pp. 181-210). New York, NY: Psychology Press.

Zagona, K. (2003). Tense and anaphora: Is there a tense-specific theory of coreference? In A. Barrs (Ed.), Anaphora: A reference guide (pp. 140-171). Oxford: Blackwell Publishing.

Zagona, K. (2013). Tense, aspect, and modality. In M. den Dikken (Ed.), The Cambridge handbook of generative syntax (pp. 746-792). Cambridge: Cambridge University Press. 


\footnotetext{
${ }^{1}$ The hypotheses discussed here were originally formulated for agrammatic aphasia (Bastiaanse et al., 2011; Fyndanis et al., 2012) but there is evidence that they can also account for patterns of performance exhibited by individuals with non-agrammatic aphasia (see, for example, the three individuals with transcortical motor aphasia reported by Rofes, Bastiaanse, \& Martínez-Ferreiro, 2014, as well P1 and P7 reported by Varlokosta et al., 2006).

${ }^{2}$ In Greek, regular verbs are those whose past tense formation is rule-governed (see Ralli, 1988). In Italian, regular verbs are those that form the past participle by changing the suffix of their infinitival form only (e.g., am-a-re (infinitive) $>a m$-a-to (past participle), dorm-i-re (infinitive) $>$ dorm-i-to (past participle)) (Colombo et al., 2009).
} 


\section{TABLE 1}

Demographic and cognitive profile (selection) of Greek- and Italian-speaking participants.

\begin{tabular}{|c|c|c|c|c|c|c|c|}
\hline & Age & $\begin{array}{l}\text { Edu } \\
\text { (yrs) }\end{array}$ & Sex & $\begin{array}{l}\text { MMSE } \\
(\max 30)\end{array}$ & $\begin{array}{l}\text { Digit ordering } \\
\text { span task } \\
(\max 15)\end{array}$ & $\begin{array}{l}\text { Backward digit } \\
\text { span task } \\
(\max 14)\end{array}$ & $\begin{array}{l}\text { Verbal WM } \\
\text { total } \\
(\max 29)\end{array}$ \\
\hline Mean Greek & 76.6 & 6.1 & n.a. & 17.7 & 5.9 & 2.8 & 8.6 \\
\hline $\mathrm{AD}$ group & $( \pm 8.3)$ & $( \pm 4.2)$ & & $( \pm 4.1)$ & $( \pm 3.9)$ & $( \pm 1.7)$ & $( \pm 4.9)$ \\
\hline Mean Greek & 76.3 & 5.8 & n.a. & 29.5 & 10.1 & 5.3 & 15.4 \\
\hline control group & $( \pm 7.8)$ & $( \pm 3.3)$ & $(13 \mathrm{~F})$ & $( \pm 0.9)$ & $( \pm 3.2)$ & $( \pm 1.5)$ & $( \pm 4)$ \\
\hline Mean Italian & 78.6 & 8.6 & n.a. & 22.6 & 4.2 & 2.7 & 6.9 \\
\hline $\mathrm{AD}$ group & $( \pm 4.3)$ & $( \pm 6)$ & $(5 \mathrm{~F})$ & $( \pm 2.3)$ & $( \pm 1.9)$ & $( \pm 1.2)$ & $( \pm 2.9)$ \\
\hline Mean Italian & 75 & 10.8 & n.a. & 28.9 & 11.5 & 5.3 & 16.8 \\
\hline control group & $( \pm 6.9)$ & $( \pm 4.8)$ & $(5 \mathrm{~F})$ & $( \pm 0.8)$ & $( \pm 1.6)$ & $( \pm 2.1)$ & $( \pm 2.9)$ \\
\hline
\end{tabular}

6

7 
TABLE 2

Greek-speaking participants' performance: Count data (correct performance), percent accuracy, Standard Deviation, and Confidence Intervals.

\begin{tabular}{|c|c|c|c|c|c|c|c|}
\hline & $\begin{array}{l}\text { Agr } \\
(\mathrm{N}=40)\end{array}$ & $\begin{array}{l}\mathrm{TR} \\
(\mathrm{N}=40)\end{array}$ & $\begin{array}{l}\mathrm{M} \\
(\mathrm{N}=60)\end{array}$ & $\begin{array}{l}\text { Past Ref. } \\
(\mathrm{N}=20)\end{array}$ & $\begin{array}{l}\text { Future Ref. } \\
(\mathrm{N}=20)\end{array}$ & $\begin{array}{l}\text { Indic. } M \\
(\mathrm{~N}=30)\end{array}$ & $\begin{array}{l}\text { Subj. M } \\
(\mathrm{N}=30)\end{array}$ \\
\hline \multicolumn{8}{|l|}{$A D$} \\
\hline \multirow[t]{2}{*}{$\mathrm{P} 1$} & $39 *$ & $35^{*}$ & $56^{*}$ & $17^{*}$ & $18^{*}$ & $29 *$ & $27^{*}$ \\
\hline & $(98 \%)$ & $(88 \%)$ & $(93 \%)$ & $(85 \%)$ & $(90 \%)$ & $(97 \%)$ & $(90 \%)$ \\
\hline \multirow[t]{2}{*}{$\mathrm{P} 2$} & $39 *$ & 40 & 60 & 20 & 20 & 30 & 30 \\
\hline & $(98 \%)$ & $(100 \%)$ & $(100 \%)$ & $(100 \%)$ & $(100 \%)$ & $(100 \%)$ & $(100 \%)$ \\
\hline \multirow[t]{2}{*}{ P3 } & 40 & 38 & 60 & 19 & 19 & 30 & 30 \\
\hline & $(100 \%)$ & $(95 \%)$ & $(100 \%)$ & $(95 \%)$ & $(95 \%)$ & $(100 \%)$ & $(100 \%)$ \\
\hline \multirow[t]{2}{*}{ P4 } & $38^{*}$ & $37 *$ & $54^{*}$ & 20 & $17 *$ & 30 & $24^{*}$ \\
\hline & $(95 \%)$ & $(93 \%)$ & $(90 \%)$ & $(100 \%)$ & $(85 \%)$ & $(100 \%)$ & $(80 \%)$ \\
\hline \multirow[t]{2}{*}{ P5 } & 40 & 40 & 60 & 20 & 20 & 30 & 30 \\
\hline & $(100 \%)$ & $(100 \%)$ & $(100 \%)$ & $(100 \%)$ & $(100 \%)$ & $(100 \%)$ & $(100 \%)$ \\
\hline \multirow[t]{2}{*}{ P6 } & $36^{*}$ & $19 *$ & 49 & $2^{*}$ & $17^{*}$ & $29 *$ & $20 *$ \\
\hline & $(90 \%)$ & $(48 \%)$ & $(82 \%)$ & $(10 \%)$ & $(85 \%)$ & $(97 \%)$ & $(67 \%)$ \\
\hline \multirow[t]{2}{*}{ P7 } & $39 *$ & 40 & 58 & 20 & 20 & 30 & 28 \\
\hline & $(98 \%)$ & $(100 \%)$ & $(97 \%)$ & $(100 \%)$ & $(100 \%)$ & $(100 \%)$ & $(93 \%)$ \\
\hline \multirow[t]{2}{*}{ P8 } & 40 & 40 & 60 & 20 & 20 & 30 & 30 \\
\hline & $(100 \%)$ & $(100 \%)$ & $(100 \%)$ & $(100 \%)$ & $(100 \%)$ & $(100 \%)$ & $(100 \%)$ \\
\hline \multirow[t]{2}{*}{ P9 } & $39 *$ & 39 & 60 & 19 & 20 & 30 & 30 \\
\hline & $(98 \%)$ & $(98 \%)$ & $(100 \%)$ & $(95 \%)$ & $(100 \%)$ & $(100 \%)$ & $(100 \%)$ \\
\hline
\end{tabular}




\begin{tabular}{|c|c|c|c|c|c|c|c|}
\hline \multirow[t]{2}{*}{ P10 } & $39 *$ & 40 & 60 & 20 & 20 & 30 & 30 \\
\hline & $(98 \%)$ & $(100 \%)$ & $(100 \%)$ & $(100 \%)$ & $(100 \%)$ & $(100 \%)$ & $(100 \%)$ \\
\hline \multirow[t]{2}{*}{ P11 } & $38^{*}$ & 38 & 58 & 18 & 20 & 30 & 28 \\
\hline & $(95 \%)$ & $(95 \%)$ & $(97 \%)$ & $(90 \%)$ & $(100 \%)$ & $(100 \%)$ & $(93 \%)$ \\
\hline \multirow[t]{2}{*}{ P12 } & $39^{*}$ & 39 & $56^{*}$ & 20 & 19 & 30 & $26^{*}$ \\
\hline & $(98 \%)$ & $(98 \%)$ & $(93 \%)$ & $(100 \%)$ & $(95 \%)$ & $(100 \%)$ & $(87 \%)$ \\
\hline \multirow[t]{2}{*}{ P13 } & $35^{*}$ & $12 *$ & $56^{*}$ & $2 *$ & $10^{*}$ & 30 & $26^{*}$ \\
\hline & $(88 \%)$ & $(30 \%)$ & $(93 \%)$ & $(10 \%)$ & $(50 \%)$ & $(100 \%)$ & $(87 \%)$ \\
\hline \multirow[t]{2}{*}{ P14 } & $37 *$ & $24 *$ & 59 & $4^{*}$ & 20 & 30 & 29 \\
\hline & $(93 \%)$ & $(60 \%)$ & $(98 \%)$ & $(20 \%)$ & $(100 \%)$ & $(100 \%)$ & $(97 \%)$ \\
\hline \multirow[t]{2}{*}{ P15 } & 40 & 39 & 60 & 20 & 19 & 30 & 30 \\
\hline & $(100 \%)$ & $(98 \%)$ & $(100 \%)$ & $(100 \%)$ & $(95 \%)$ & $(100 \%)$ & $(100 \%)$ \\
\hline \multirow[t]{2}{*}{ P16 } & $39^{*}$ & $35^{*}$ & 58 & 18 & $17^{*}$ & 30 & 28 \\
\hline & $(98 \%)$ & $(88 \%)$ & $(97 \%)$ & $(90 \%)$ & $(85 \%)$ & $(100 \%)$ & $(93 \%)$ \\
\hline \multirow[t]{4}{*}{ TOTAL } & $617 / 640$ & $555 / 640$ & $924 / 960$ & $259 / 320$ & $296 / 320$ & $478 / 480$ & $446 / 480$ \\
\hline & $(96.41 \%$ & $(86.72 \%$ & $(96.25 \%$ & $(80.94 \%$ & (92.5\% & $(99.58 \%$, & $(92.92 \%$ \\
\hline & \pm 3.61 & \pm 21.41 & \pm 5.01 & \pm 33.92 & \pm 12.78 & \pm 1.02 & \pm 9.26 \\
\hline & $\pm 1.77)$ & $\pm 10.49)$ & $\pm 2.45)$ & $\pm 16.62)$ & $\pm 6.26)$ & $\pm 0.5)$ & $\pm 4.54)$ \\
\hline \multicolumn{8}{|l|}{ Controls } \\
\hline \multirow[t]{4}{*}{ TOTAL } & $640 / 640$ & $635 / 640$ & $956 / 960$ & $316 / 320$ & $319 / 320$ & $480 / 480$ & $476 / 480$ \\
\hline & $(100 \%$ & $(99.22 \%$ & $(99.58 \%$ & $(98.75 \%$, & $(99.69 \%$ & $(100 \%$ & $(99.17 \%$ \\
\hline & \pm 0 & \pm 1.73 & \pm 1.02 & \pm 2.89 & \pm 1.25 & \pm 0 & \pm 2.39 \\
\hline & $\pm 0)$ & $\pm 0.85)$ & $\pm 0.5)$ & $\pm 1.42)$ & $\pm 0.61)$ & $\pm 0)$ & $\pm 1.17)$ \\
\hline
\end{tabular}


Note: Agr $=$ subject-verb Agreement, $\mathrm{TR}=$ Time Reference, $\mathrm{M}=$ Mood, Past Ref. $=$ Past

Reference, Future Ref. $=$ Future Reference, Indic. $M=$ Indicative Mood, Subj. $M=$ Subjunctive Mood

*indicates performance outside the normal range (= range of control participants' performance) 
TABLE 3

Logit mixed-effect models on Greek-speaking AD and control participants' accuracy in the Time Reference condition. Model 4, fitted to the dataset of participants with AD, included Time Reference (two levels: Past Reference, Future Reference) as a fixed effect, a random intercept for Subjects $(\mathrm{SD}=1.44)$, a random intercept for Items $(\mathrm{SD}=0.00)$, and Time Reference as by-Subject random slope. Model 3, fitted to the dataset of control participants, included Time Reference (two levels: Past Reference, Future Reference) as a fixed effect, a random intercept for Subjects $(\mathrm{SD}=6.34)$, and a random intercept for Items $(\mathrm{SD}=7.74)$.

\begin{tabular}{llllc}
\hline Term & $\boldsymbol{\beta}$ & Standard Error & z-value & p-value \\
\hline Dataset of participants with AD & & & & \\
(Intercept; Condition=Future Ref.) & 3.34 & 0.56 & 6.00 & $<0.001^{*}$ \\
Condition=Past Ref. & 0.40 & 1.10 & 0.37 & 0.715 \\
\hline Dataset of control participants & & & & \\
(Intercept; Condition=Future Ref.) & 16.89 & 4.58 & 3.69 & $<0.001^{*}$ \\
Condition=Past Ref. & -1.24 & 3.00 & -0.41 & 0.679 \\
\hline
\end{tabular}

* Indicates significant effects. 
TABLE 4

Italian-speaking participants' performance: Count data (correct performance), percent accuracy, Standard Deviation, and Confidence Intervals.

\begin{tabular}{|c|c|c|c|c|c|c|c|}
\hline & $\begin{array}{l}\text { Agr } \\
(\mathrm{N}=40)\end{array}$ & $\begin{array}{l}\mathrm{TR} \\
(\mathrm{N}=40)\end{array}$ & $\begin{array}{l}M \\
(N=60)\end{array}$ & $\begin{array}{l}\text { Past Ref. } \\
(\mathrm{N}=20)\end{array}$ & $\begin{array}{l}\text { Future Ref. } \\
(\mathrm{N}=20)\end{array}$ & $\begin{array}{l}\text { Indic. } \mathrm{M} \\
(\mathrm{N}=30)\end{array}$ & $\begin{array}{l}\text { Subj. M } \\
(\mathrm{N}=30)\end{array}$ \\
\hline$A D$ & 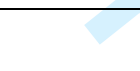 & & & & & & \\
\hline P1 & $\begin{array}{l}39 \\
(98 \%)\end{array}$ & $\begin{array}{l}40 \\
(100 \%)\end{array}$ & $\begin{array}{l}56 \\
(93 \%)\end{array}$ & $\begin{array}{l}20 \\
(100 \%)\end{array}$ & $\begin{array}{l}20 \\
(100 \%)\end{array}$ & $\begin{array}{l}26 \\
(87 \%)\end{array}$ & $\begin{array}{l}30 \\
(100 \%)\end{array}$ \\
\hline P2 & - & - & $\begin{array}{l}30 * \\
(50 \%)\end{array}$ & - & - & $\begin{array}{l}30 \\
(100 \%)\end{array}$ & $\begin{array}{l}0^{*} \\
(0 \%)\end{array}$ \\
\hline P3 & $\begin{array}{l}38 \\
(95 \%)\end{array}$ & $\begin{array}{l}40 \\
(100 \%)\end{array}$ & $\begin{array}{l}42 \\
(70 \%)\end{array}$ & $\begin{array}{l}20 \\
(100 \%)\end{array}$ & $\begin{array}{l}20 \\
(100 \%)\end{array}$ & $\begin{array}{l}30 \\
(100 \%)\end{array}$ & $\begin{array}{l}12 * \\
(40 \%)\end{array}$ \\
\hline P4 & $\begin{array}{l}38 \\
(95 \%)\end{array}$ & $\begin{array}{l}38^{*} \\
(95 \%)\end{array}$ & $\begin{array}{l}42 \\
(70 \%)\end{array}$ & $\begin{array}{l}18 * \\
(90 \%)\end{array}$ & $\begin{array}{l}20 \\
(100 \%)\end{array}$ & $\begin{array}{l}26 \\
(87 \%)\end{array}$ & $\begin{array}{l}16^{*} \\
(53 \%)\end{array}$ \\
\hline P5 & $\begin{array}{l}39 \\
(98 \%)\end{array}$ & $\begin{array}{l}40 \\
(100 \%)\end{array}$ & $\begin{array}{l}38 \\
(63 \%)\end{array}$ & $\begin{array}{l}20 \\
(100 \%)\end{array}$ & $\begin{array}{l}20 \\
(100 \%)\end{array}$ & $\begin{array}{l}10 \\
(33 \%)\end{array}$ & $\begin{array}{l}28 \\
(93 \%)\end{array}$ \\
\hline P6 & $\begin{array}{l}33 * \\
(83 \%)\end{array}$ & $\begin{array}{l}19 * \\
(48 \%)\end{array}$ & $\begin{array}{l}21 * \\
(35 \%)\end{array}$ & $\begin{array}{l}1 * \\
(5 \%)\end{array}$ & $\begin{array}{l}18^{*} \\
(90 \%)\end{array}$ & $\begin{array}{l}15 \\
(50 \%)\end{array}$ & $\begin{array}{l}6^{*} \\
(20 \%)\end{array}$ \\
\hline P7 & $\begin{array}{l}15^{*} \\
(38 \%)\end{array}$ & $\begin{array}{l}8^{*} \\
(20 \%)\end{array}$ & $\begin{array}{l}2 * \\
(3 \%)\end{array}$ & $\begin{array}{l}6^{*} \\
(30 \%)\end{array}$ & $\begin{array}{l}2 * \\
(10 \%)\end{array}$ & $\begin{array}{l}0 * \\
(0 \%)\end{array}$ & $\begin{array}{l}2 * \\
(7 \%)\end{array}$ \\
\hline P8 & - & - & $\begin{array}{l}32 * \\
(53 \%)\end{array}$ & - & - & $\begin{array}{l}12 \\
(40 \%)\end{array}$ & $\begin{array}{l}20 \\
(67 \%)\end{array}$ \\
\hline P9 & $\begin{array}{l}35 * \\
(88 \%)\end{array}$ & $\begin{array}{l}40 \\
(100 \%)\end{array}$ & $\begin{array}{l}42 \\
(70 \%)\end{array}$ & $\begin{array}{l}20 \\
(100 \%)\end{array}$ & $\begin{array}{l}20 \\
(100 \%)\end{array}$ & $\begin{array}{l}26 \\
(87 \%)\end{array}$ & $\begin{array}{l}16^{*} \\
(53 \%)\end{array}$ \\
\hline P10 & $36^{*}$ & $26^{*}$ & $33^{*}$ & $10 *$ & $16^{*}$ & 17 & $16^{*}$ \\
\hline
\end{tabular}




\section{TABLE 5}

Logit mixed-effect model on Italian-speaking participants' accuracy on Agreement, Time Reference, and Mood. This model included the additive effect of Morphosyntactic Condition (three levels: Agreement, Time Reference, Mood) and Group (two levels: Participants with AD, Control participants), and the interaction between the two. The model also included a random intercept for Subjects $(\mathrm{SD}=1.32)$ and a random intercept for Items $(\mathrm{SD}=0.67)$. (Model 1)

\begin{tabular}{lllll}
\hline Term & $\boldsymbol{\beta}$ & Standard Error & z-value & p-value \\
\hline (Intercept; Condition=Agreement; Group=AD) & 2.61 & 0.49 & 5.39 & $<0.001^{*}$ \\
Condition=Mood & -2.33 & 0.28 & -8.27 & $<0.001^{*}$ \\
Condition=Time Ref. & -0.75 & 0.30 & -2.49 & $0.01^{*}$ \\
Group=Control & 2.05 & 0.71 & 2.89 & $<0.01^{*}$ \\
\hline Condition=Mood : Group=Control & 0.12 & 0.43 & 0.29 & 0.77 \\
Condition=Time Ref. : Group=Control & 2.88 & 1.04 & 2.77 & $<0.01^{*}$ \\
\hline Intercept; Condition=Mood; Group=AD) & 0.28 & 0.44 & 0.64 & 0.52 \\
Condition=Agreement & 2.33 & 0.28 & 8.27 & $<0.001^{*}$ \\
Condition=Time Ref. & 1.58 & 0.25 & 6.25 & $<0.001^{*}$ \\
Group=Control & 2.17 & 0.61 & 3.57 & $<0.001^{*}$ \\
\hline Condition=Agreement : Group=Control & -0.12 & 0.43 & -0.29 & 0.77 \\
Condition=Time Ref. : Group=Control & 2.75 & 0.98 & 2.81 & $<0.01^{*}$ \\
\hline
\end{tabular}

* Indicates significant effects. 


\section{TABLE 6}

Logit mixed-effect model on Italian-speaking participants' accuracy in the Mood condition. This model included the additive effect of Mood and Group, the interaction between the two, a random intercept for Subjects $(\mathrm{SD}=1.30)$, and a random intercept for Items $(\mathrm{SD}=0.37)$. (Model 1)

\begin{tabular}{lllll}
\hline Term & $\boldsymbol{\beta}$ & Standard & z-value & p-value \\
& & Error & \\
\hline (Intercept; Mood=Indicative; & 0.67 & 0.44 & 1.52 & 0.128 \\
Group=AD) & & & & \\
Mood=Subjunctive & -0.81 & 0.21 & -3.79 & $<0.001^{*}$ \\
Group=Control & 2.06 & 0.63 & 3.29 & $0.001^{*}$ \\
\hline Mood=Subjunctive : Group=Control & -0.23 & 0.31 & 0.73 & 0.465 \\
\hline * Indicates significant effects. & & & &
\end{tabular}




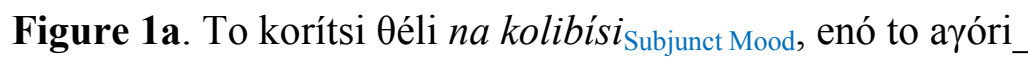
. (target: kolibái $i_{\text {Indicat }}$ Mood) 'The girl wants to swim, while the boy .' (target: is swimming)

6
7

8

9

10

11

12

13

14

15

16

17

18

19

20

21

22

23

24

25

26

27

28

29

30

31

32

33

34

35

36

37

38

39

40

41

42

43

44

45

46

47

48

49

50

51

52

53

54

55

56

57

58

59

60

URL: http://mc.manuscriptcentral.com/paph Email: c.f.s.code@exeter.ac.uk 


\section{Page 55 of 56}

1

2

3

4

5

6

7

8

9

10

11

12

13

14

15

16

17

18

19

20

21

22

23

24

25

26

27

28

29

30

31

32

33

34

35

36

37

38

39

40

41

42

43

44

45

46

47

48

49

50

51

52

53

54

55

56

57

58

59

60

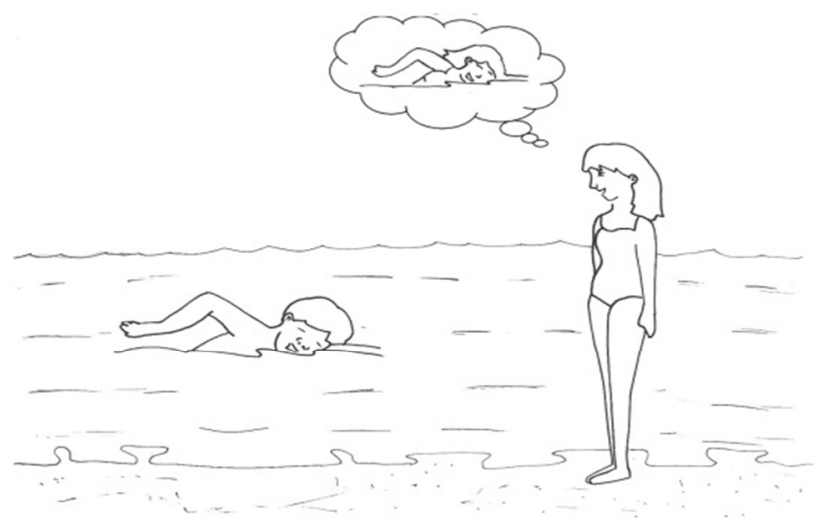

Aphasiology

(2)

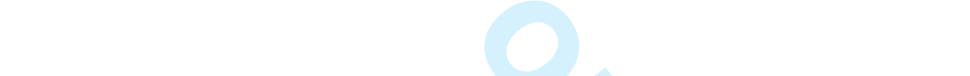




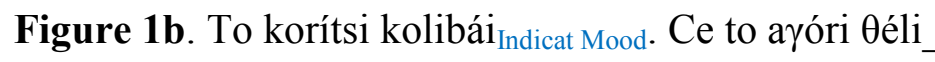
. (target: na kolibísi $i_{\text {Subjunct }}$ Mood) 'The girl is swimming. Also the boy wants .' (target: to swim)

1

2

5

6

7

8

9

10

11

12

13

14

15

16

17

18

19

20

21

22

23

24

25

26

27

28

29

30

31

32

33

34

35

36

37

38

39

40

41

42

43

44

45

46

47

48

49

50

51

52

53

54

55

56

57

58

59

60 
1

2

3

4

5

6

7

8

9

10

11

12

13

14

15

16

17

18

19

20

21

22

23

24

25

26

27

28

29

30

31

32

33

34

35

36

37

38

39

40

41

42

43

44

45

46

47

48

49

50

51

52

53

54

55

56

57

58

59

60

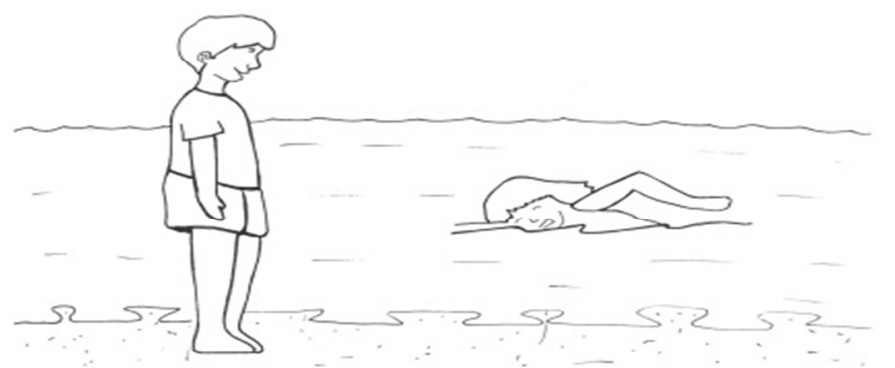

